\title{
DISTRIBUTION OF ALVEOLAR EDEMA IN VENTILATED AND UNVENTILATED CANINE LUNG LOBES
}

BY

DAN M. IANCU, MD

A thesis submitted to the Faculty of Graduate Studies and Research in partial fulfilment of the requirements for the degree of Master of Science.

(c) Dan M. IANCU, May 1994.

Faculty of Medicine,

Department of Pathology,

McGill University,

Montreal, Quebec, Canada. 
TABLE OF CONTENTS

TITLE PAGE

PAGE

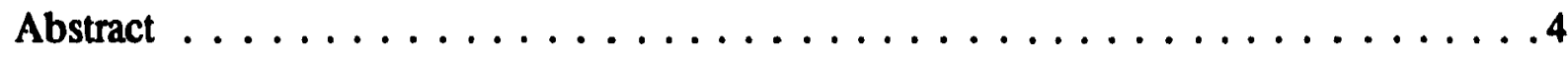

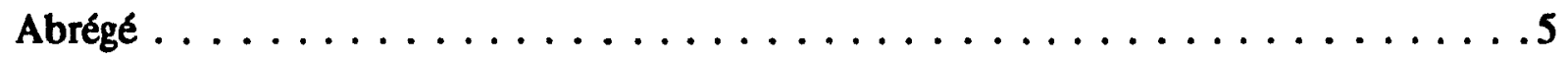

Chapter 1: INTRODUCTION $\ldots \ldots \ldots \ldots \ldots \ldots \ldots \ldots \ldots \ldots \ldots \ldots \ldots$

Clinical importance of pulmonary edema $\ldots \ldots \ldots \ldots \ldots \ldots \ldots$

Classification, sequence and pathways of accumulation of pulmonary edema $\ldots \ldots 8$

Clearance of pulmonary edema $\ldots \ldots \ldots \ldots \ldots \ldots$

Role of ventilation in treatment and clearance of lung edema $\ldots \ldots \ldots \ldots$

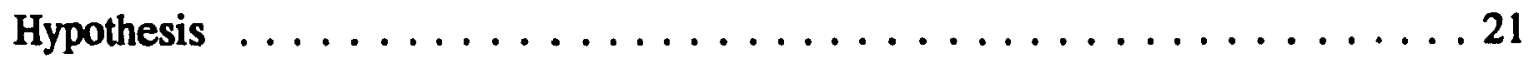

Objectives ......................... 22

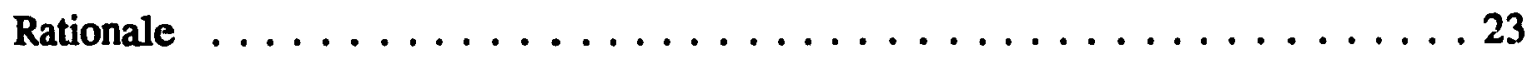

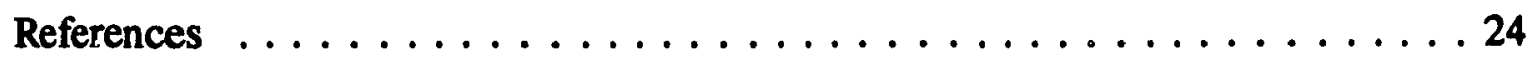

Chapter 2: DISTRIBUTION OF ALVEOLAR EDEMA IN VENTILATED AND

UNVENTILATED CANINE LUNG LOBES $\ldots \ldots \ldots \ldots \ldots$

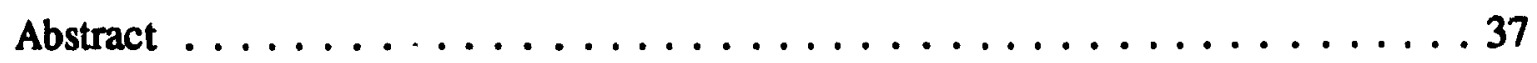

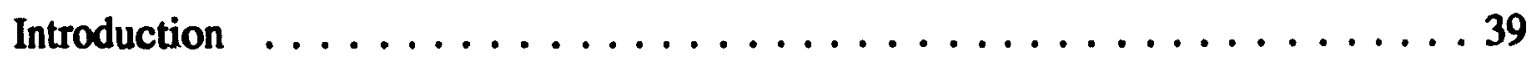

Materials and methods $\ldots \ldots \ldots \ldots \ldots \ldots \ldots \ldots \ldots \ldots \ldots$ 
3

Results ..........................47

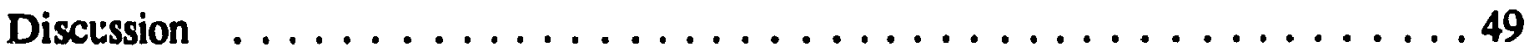

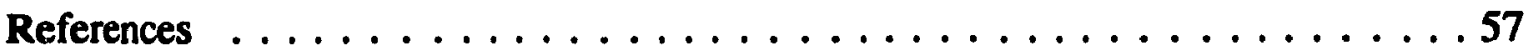

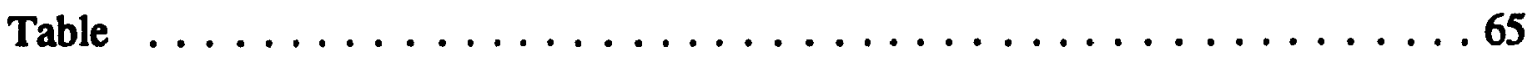

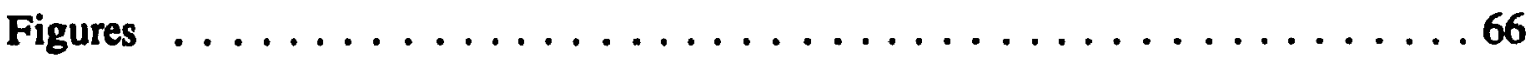

Chapter 3: CONCLUSIONS $\ldots \ldots \ldots \ldots \ldots \ldots \ldots \ldots \ldots$

APPENDIX I : ABBREVIATIONS $\ldots \ldots \ldots \ldots \ldots \ldots \ldots \ldots \ldots$

APPENDIX II : SI. UNIT EQUIVALENTS $\ldots \ldots \ldots \ldots \ldots \ldots \ldots \ldots \ldots$

APPENDIX III : ACKNOWLEDGEMENTS $\ldots \ldots \ldots \ldots \ldots \ldots$ 


\begin{abstract}
Ventilation is frequently used in the treatment of cardiogenic and increased permeability pulmonary edema. The effects of ventilation on the computed tomography (CT) density distribution of pulmonary edema are unclear. We hypothesized that ventilation might open up previously collapsed alveoli with consequent reduced lung density, and that some movement of the alveolar edema fluid might also occur from the alveoli to the interstitium. To address this problem, pulmonary edema was induced in 16 supine dogs by airways instillation of a protein solution similar to serum in each lower lung lobe through a double lumen tracheal tube. The dogs were ventilated only on the left side for $1 \mathrm{~min}(n=4), 30 \mathrm{~min}$ $(n=6)$ or $60 \min (n=6)$. The lower lobes were excised, frozen in liquid nitrogen, and imaged in a CT scanner. Representative regions of interest (ROI) were chosen and tissue sections from corresponding regions were taken for extravascular lung water ( $\mathrm{Qwl} / \mathrm{dQl})$ and regional blood measurements, and for histology to grade interstitial and alveolar edema. There was a significant $(P<0.05)$ fall in the CT density of the left lower lobes compared with the right lower lobes in the groups ventilated 30 and $60 \mathrm{~min}$, but no differences in QwildQl or blood content. The histological grading showed a trend $(P=0.054)$ for more interstitial edema in the left lower lobes in the 60 min ventilation group compared with left lower lobes in the $1 \mathrm{~min}$ ventilation group. These data show that in our model of instilled alveolar edema, ventilation acts primarily by increasing aeration by $30 \mathrm{~min}$ and that it has a minor role in moving fluid to the interstitium.
\end{abstract}




\section{ABREGÉ}

La ventilation est fréquemment utilisée lors du traitement de l'oedème pulmonaire cardiogénique ou à perméabilité accrue. Les effets de la ventilation sur la distribution de la densité de l'oedème pulmonaire à la tomographie à balayage informatisée (CT) sont peu claires. Nous avons proposé l'hypothèse que la ventilation ouvre des alvéoles préalablement fermées conduisant à une réduction de la densité pulmonaire, ainsi qu'au mouvement du liquide des alvéoles vers l'interstitium. Afin d'étudier ce problème, un oedème pulmonaire fut induit chez 16 chiens en supination par l'instillation d'une solution protéinique semblable au sérum dans chacun des lobes inférieurs des poumons par un tube trachéal à double ouverture. Les chiens furent ventilés uniquement du côté gauche pendant $1 \mathrm{~min}(n=4), 30$ $\min (n=6)$ ou $60 \min (n=6)$. Les lobes inférieurs furent ensuite excisés, congelés dans l'azote liquide, et examinés au CT. Des régions d'intérêt ont été sélectionnées et des sections tissulaires des régions correspondantes furent prélevées pour mesurer l'eau pulmonaire extravasculaire (Qwl/dQl) et le contenu en sang, de même que pour histologie pour évaluer le degré d'oedème interstitiel et alvéolaire. Nous avons constaté une baisse dramatique $(P<0.05)$ de la densité tomographique des lobes inférieurs gauches en comparaison avec ceux de droite chez les groupes ventilés pendant 30 et 60 min mais sans differences de $\mathrm{Qwl} / \mathrm{dQl}$. L'évaluation histologique a démontré une augmentation $(\mathrm{P}=0.054)$ de l'oedème interstitiel dans les lobes inférieurs gauches du groupe ventilé pour 60 minutes, comparé aux mêmes lobes du groupe ventilé pendant $1 \mathrm{~min}$. Ces résultats démontrent que dans notre modèle d'oedème alvéolaire instillé, la ventilation agit principalement en augmentant l'aération a 30 min et que cependant elle joue un rôle mineur dans le transport des fluides vers l'interstitium. 
CHAPTER 1

NTRODUCTION 
Edema, defined as an increase in extravascular water, may occur in any tissue, but has life-threatening consequences in the lung, especially in its alveolar flooding phase.

\section{Clinical importance of pulmonary edema}

Pulmonary edema is an extremely common clinical condition for the following reasons (1). First, heart disease is the leading cause of death in the United States and Canada and during the course of cardiac decompensation, a patient may be in and out of pulmonary edema, varying with the chronicity of his disease, from dozens to hundreds of times. Cardiogenic pulmonary edema is the cause of about two thirds of clinical cases of pulmonary edema and has a mortality of $17-36 \%$ that is directly related to alveolar flooding $(2,3)$. Second, with the virtually universal use of intravenous fluid therapy for resuscitation, replenishment, and parenteral nutrition, overhydration pulmonary edema has become very common. Third, with the advent of renal transplantation and dialysis, patients with renal disease are surviving for long periods of time, and pulmonary edema associated with renal disease is common. Fourth, the adult respiratory distress syndrome (ARDS), an important cause of increased permeability edema, affects 150,000 patients per year in the USA with a mortality of over 50\% (4-6). Pulmonary edema also occurs in association with infectious lung diseases, drug and transfusion reactions. In the United States, approximately $25 \%$ of the 70 million chest roentgenograms taken each year are for cardiac diseases and other causes of pulmonary edema. 


\section{Classification, sequence and pathways of accumulation of pulmonary edema}

The anatomy of the fluid compartments in the lung has been reviewed by Casaburi et al (7). Both vascular and tissue compartments are composed of $\sim 80 \%$ water. In the normal lung, extravascular water $(\mathrm{Qwl} / \mathrm{dQl})$ is about evenly divided between the interstitial space and the cellular compartment and is estimated to be $3.5-4.0 \mathrm{~g} \mathrm{H}_{2} \mathrm{O} / \mathrm{g}$ dry lung tissue (8). $\mathrm{Qwl} / \mathrm{dQl}$ is calculated from lung wet weight/dry weight ratio, corrected for blood water as explained by Staub (8). Elevation of Qwl/dQl indicates the presence of edema, either in the interstitium or in the air spaces. In the normal lung, fluid is exchanged between the pulmonary circulation, the interstitium and the lymphatics.

Fluid filtration across the pulmonary microvascular bed is determined by the Starling equation which can be enunciated as follows (8):

$$
Q_{f}=K_{f c}\left[\left(P_{c}-P_{t s}\right)-\sigma_{d}\left(\pi_{c}-\pi_{t s}\right)\right]=K_{f c}[\Delta P]
$$

It shows the relationship between the net fiuid flux across the microvascular bed $\left(Q_{f}\right)$ and the net pressure drop $(\Delta \mathrm{P})$ across the capillary wall. The pressures causing liquid and protein to move out of the vascular space into the interstitium are the hydrostatic pressure in the capillary $\left(\mathrm{P}_{c}\right)$ and the oncotic pressure of the interstitial space $\left(\boldsymbol{\pi}_{\mathrm{b}}\right)$, which normally are offset by the pressures tending to move fluid back in the vasculature, ie. the algebraic sum of the hydrostatic pressure in the interstitial space $\left(\mathrm{P}_{\mathrm{ta}}\right)$ and oncotic pressure of the plasma $\left(\pi_{\mathrm{c}}\right) . \mathrm{K}_{\mathrm{fc}}$, the capillary filtration coefficient, is directly related to membrane area and pore radius to the fourth power and inversely related to membrane thickness and viscosity of the fluid being filtered $(9-11) . \quad \sigma_{d}$, the reflection coefficient, is a measure of the permeability of a given membrane to a given solute. It varies from 0 , when, in the lung for example, the capillary 
membrane is freely permeable to albumin, to 1 when it is completely impermeable to it $(11,12)$.

Normally in the lung, there is a net outward filtration of fluid (13). In sheep, the normal steady-state filtration of pulmonary fluid is $5-10 \mathrm{ml} / \mathrm{h}$, measured as the flow of pulmonary lymph $(11,14)$. The filtration of fluid cannot be measured directly in humans, but is estimated to be 10 to $20 \mathrm{ml} / \mathrm{h}$ in adults (14). Therefore, when the lung neither gains nor loses weight, the amount of fluid leaving the capillaries exactly equals lymph flow (11).

On the basis of Starling's equation, two clinically important forms of edema, hydrostatic and permeability, may be distinguished $(8,15)$. Hydrostatic pulmonary edema develops because of an elevated pressure in the lung microcirculation, usually due to causes such as left-sided heart failure, mitral stenosis, ischemic heart disease, etc. Other causes of increased lung microvascular pressure are veno-occlusive disease and fluid overload; more negative interstitial pressure caused by reexpansion of a hemothorax or pneumothorax, and decreased oncotic pressure due to hypoalbuminemic states are rarer causes. Classically, in hydrostatic edema, the morphology of the alveolo-capillary endothelium and epithelium are normal and the protein concentration of the edema fluid is low $(16,17)$.

Increased permeability edema, in contrast, results from an increased $\sigma_{d}$ and/or $K_{\text {fo }}$, generally due to injury of the endothelium and/or epithelium with leakage of a protein-rich edema fluid (18-20). Permeability edema is commonly encountered, as indicated above, in patients with infections, drug overdose, gastric aspiration, toxic gas inhalation and with the ARDS. 
In the lung, due to its particular anatomy, edema fluid tends to accumulate in an orderly sequence (21). As microvascular pressure rises, the initial stage is pulmonary vascular congestion characterized by an increase in blood volume without a rise in Qwl/dQl. Direct measurements of blood volume in normal adult lungs at necropsy hive been made by Backmann and Hartung (22) from estimates of hemoglobin content, and provide an average figure of $508 \pm 120 \mathrm{ml}$. This volume increases with congestion, producing a rise in lung density and a decrease in its compliance. Congestion has minimal effects on gas exchange $(23,24)$.

The second stage is interstitial edema that occurs at left atrial pressures of about 16 to 22 $\mathrm{mm} \mathrm{Hg}$ when the excess filtered fluid entering the pulmonary interstitium exceeds the capacity of the lymphatics (25). Lymph flow can increase approximately 20 times above baseline value in states of chronic microvascular pressure elevation to prevent interstitial edema formation (26). Pulmonary lymphatics are thought to play a major role in the prevention of interstitial edema, but not in its resolution phase (see below). Several authors have reported that lymph flow is determined mainly by the microvascular filtration and reflects events in the immediate perimicrovascular interstitium rather than in the sequestered cuffs around bronchovascular bundles (27-29). Mitzner and Sylvester (28) introduced the concept of a two-compartment interstitial space: the first compartment is the perimicrovascular space that is small and non-compliant, accommodates the fluid filtered from the microvasculature and directly contributes to and affects lymph flow. As excess filtration continues, however, and the pressure increases in this first compartment, edema fluid starts to fill the second larger compartment that includes the extraalveolar interstitial 
space around airways and vessels, and interlobular septa that do not communicate with the lymphatics (30).

This second interstitial compartment is very compliant in pulmonary edema. Interstitial extravascular lung water $(\mathrm{Qwl} / \mathrm{dQl})$ can generally increase up to $35 \%$ prior to alveolar flooding (31-35). Therefore, it is an important safety factor that protects against alveolar flooding. Staub et al (21) demonstrated that, in the accumulation of edema, after the excess filtered fluid enters the alveolar interstitial space, it moves proximally towards the peribronchial and the perivascular space. This occurs largely because the interstitial pressure in the extraalveolar space is negative relative to that in the alveolar interstitial space and acts as a sump to drain the fluid away from the alveolar wall interstitium (36).

Several authors have studied in detail the time sequence of interstitial edema accumulation and the modulating influences. Gee et al (37) filled isolated dog lung lobes with saline for $15 \mathrm{~min}$ and found that total cuff volume, measured from photographs of the frozen lobes, increased with inflation pressure to a maximum of $2.6 \mathrm{ml} / \mathrm{g}$ dry, blood free lung. Using similar techniques, Conhaim et al (38) found the cuff capacity to be $3.4 \mathrm{ml} / \mathrm{g}$ dry lung after 1 $h$ of inflation. The difference in these results appears to be due to the different time allowed for the growth of the cuffs, and suggests that interstitial filling in liquid-inflated lobes is relatively slow. Therefore, Gee et al (37) and Conhaim et al (38) found that interstitial fluid cuffs increased with lung inflation, thereby establishing a link between edema fluid accumulation and transpulmonary pressure. Conhaim et al $(39,40)$ and Unruh et al $(41)$ investigated the time course of perivascular cuff formation and found that interstitial cuffs around vessels $>50 \mu \mathrm{m}$ diam grew at a slower rate than those around smaller vessels. 
Conhaim (40) suggested that the cuffs around larger vessels filled more slowly because of their larger capacity. Also, the arteries were more likely to have cuffs than veins. Their interpretation of this pattern is that, as a result of lobe liquid inflation, liquid entered the interstitium from the airspace in the region of the terminal airways, which are in close proximity to the smallest arteries. Liquid then flowed toward the perivenous interstitium as well as centrally toward the hilum. A similar distribution of interstitial edema was found by Michel et al (42) who induced hydrostatic edema with fluid overload and an aortic balloon in intact, close-chested anesthetized dogs. To quantify the amount of edema around arteries and veins, an "edema ratio" (computed as perivascular cuff area/vessel area) was calculated by digitizing photographs of bronchovascular bundles. The principal results of this study were that, in hydrostatic edema, interstitial fluid accumulated preferentially around arteries compared with veins and around larger ( $>400 \mu \mathrm{m})$ compared with smaller vessels. Within bronchovascular bundles, substantially more fluid was found around arteries than airways. As these findings were similar to those reported in ANTU-induced edema, Michel et al $(43,44)$ suggested that the factors responsible for the pattern of interstitial edema accumulation might be independent of the etiology and type of edema, i.e. permeability or hydrostatic.

As the interstitial perivascular and peribronchial spaces fill with fluid, the septal interstitium also swells, edema being generally confined to the thick portion of the septal interstitium containing collagen fibers $(45,46)$. The width of the thin portion of the interstitial space containing the alveolo-capillary endothelium and epithelium and the two basement membranes is increased minimally $(45,47,48)$. However, a continued increase in 
interstitial volume ( up to $-70 \%$ ) during the alveolar flooding phase of edema has been demonstrated (49). The effects of interstitial edema are still relatively minor since most patients experience only a mild degree of dyspnea with tachypnea and gas exchange starts to deterionate. The chest radiograph usually demonstrates "Kerley B lines" that are prominent interlobular sijta distended by interstitial edema $(50,51)$.

The third stage is alveolar edema. At hydrostatic pulmonary capillary pressures above 25 to $30 \mathrm{mmHg}(25)$, the safety factors provided by the reservoir capacity of interstitium are overwhelmed and the edema fluid begins to flood the alveoli $(3,18,29)$. This is the final stage of pulmonary edema. Two principal patterns of alveolar flooding in pulmonary edema, have been observed. The first pattern, in hydrostatic edema, is that since the endothelium and the epithelium are normal, the edema fluid enters the alveoli after interstitial filling by bulk flow through large channels that do not significantly sieve proteins $(16,17,19,20)$; this is based on the evidence that alveolar edema had a protein concentration close to that of plasma. This mechanism was first proposed by Staub (29) under the term of the "overflowing bathtub" theory, suggested that edema fluid enters the alveoli from the interstitium through high conductance pathways, in a retrograde direction, after interstitial pressure increases. The intercellular junctions between epithelial cells of terminal bronchioles were proposed as the leakage site. Evidence for this route of fluid entry includes the rapid movement of fluid and protein into peribronchial cuffs in fluid-filled lungs and the demonstration of electron-dense tracers in intercellular junctions between bronchiolar epithelial cells during edema formation $(19,20,52)$. Another possible site for alveolar flooding in hydrostatic edema could be the basement membranes beneath type II 
pneumocytes, known to be more permeable to macromolecules $(53,54)$. Conhaim et al (55) in recent studies, using fluorescent probes, located the leaks at the alveolar wall level.

In permeability edema, the classical sequence of edema accumulation is generally similar to that in hydrostatic edema ie. that follows the pattern described above interstitial edema occurs before alveolar flooding $(21,29)$. However, the patterns and mechanisms of alveolar flooding may differ in increased permeability edema compared with hydrostatic edema. Recent evidence suggests that in some forms of permeability edema in which there are important alterations in alveolar epithelial permeability, fluid may enter the alveoli before significant interstitial filling occurs (56). This mechanism was considered the most plausible in $\mathrm{NO}_{2}$-induced edema in dogs, in which Vassilyadi and Michel (57) found marked preferential alveolar fluoding with little if any fluid in the interstitium. Preferential alveolar flooding has also been reported in edema caused by other agents such as oleic acid that severely alter alveolo-capillary permeability $(58,59)$; in permeability edema induced by milder agents such as ANTU or alloxan, the sequence of edema accumulation resembles that seen in hydrostatic edema $(14,42-44)$.

Although classically, hydrostatic pulmonary edema is characterized by a morphologically normal endothelium and epithelium, in contrast to increased permeability pulmonary edema, recently, studies of Bachofen et al $(60,61)$ suggested the existence of closer relationships between permeability and hydrostatic pulmonary edema than previously thought. In their experimental model of hydrostatic pulmonary edema, they found changes in alveolar epithelial architecture such as unfolding of the epithelial surface, bulging of capillaries and alveolar collapse at sites of large fluid pools, the epithelial lesions occurred in areas having 
the most interstitial and alveolar edema; the endothelial cells were relatively normal. The epithelial lesions were attributed to the pressure caused by the interstitial edema and alveolar edema, and could account for some impairment in active fluid reabsorption.

Two modes of fluid accumulation in individual alveoli have been proposed. Staub (21) suggested that alveolar flooding occurs as an all-or-none phenomenon in individual alveoli, that is, there would either be relatively dry or completely flooded alveoli. More recently, however, it has been proposed that alveolar edema is a gradual process, with formation of fluid menisci of increasing thickness covering large parts of alveolar surfaces (60).

Unlike congestion and interstitial edema which have little effect on lung function, when alveolar edema occurs, there are important disturbances in gas exchange with hypoxemia, acidosis and hypercapnia related to shunting and important ventilation/perfusion abnormalities $(62,63)$.

\section{Clearance of pulmonary edema}

Recovery from pulmonary edema, specifically alveolar edema, occurs in an orderly fashion, although it is not simply the reverse of the process of formation. Havill and Gee (64) reported that alveolar edema is cleared before interstitial edema and that the first step in the removal of alveolar edema is its movement into the interstitium. There are two major impediments to the clearance of edema out of the alveoli: first, the alveolar epithelium that has tight interepithelial junctions (65-67) and second, the osmotic pressure provided by the proteins in alveoli (29). The alveolar epithelium clears crystalloids and water much faster than proteins $(67,68)$. Matthay et al $(67)$ showed that in anesthetized, ventilated sheep, the 
half time for clearance of crystalloid solutions (eg. Ringer's lactate) in sheep was $3 \mathrm{~h}$, whereas for serum instillate, it was $6 \mathrm{~h}$. In contrast, the clearance rate of ${ }^{125} \mathrm{I}$-albumin from the air space in anesthetized and unanesthetized dogs and sheep was much slower, averaging $1-1.6 \%$ per hour.

In terms of the mechanism of clearance, crystalloids, water and proteins are each cleared from the alveoli differently. Crystalloids (eg. sodium) are actively transported across the alveolar epithelium; water follows the crystalloids passively $(3,29,68,69)$. Effros et al $(70)$ showed that chloride and potassium are not reabsorbed in equal proportion to sodium and water, due probably to a simultaneous secretion process into the alveoli (71). Support of the concept that active transport was involved comes from studies showing it was increased in dogs and sheep by $B$-adrenergic agents $(72,73)$, was reduced by $50 \%$ with amiloride $(29,74)$ and prevented by ouabain (29). The meshanisms for the transalveolar clearance of proteins differ from those for crystalloids and include transcytosis $(18,75)$, diffusion and mucociliary clearance (74). The evidence to date suggests that most of the proteins are cleared as intact molecules from alveoli by transcytosis across the alveolar epithelium, and some morphological studies have demonstrated the presence of proteins within alveolar epithelial vesicles $(51,68,75-77)$. Diffusion may play a role in alveolar protein clearance, since under hypothermic conditions that inhibit transcytosis, clearance has been reported to continue at $30 \%$ of normal levels (78). Macroplages seem to have a role after $48 \mathrm{~h}$ by removing the precipitated proteins which forms hyaline membranes in the airspaces $(74,75)$. Mucociliary clea ance of protein into the proximal airways may occur, but it appears to be of minimal importance (74). 
Once the edema fluid from the alveoli reaches the lung interstitium, there are several pathways for its clearance including the lymphatics $(79,80)$, the pulmonary and bronchial circulations $(18,81-83)$, the mediastinum $(18,82)$, the pleural space $(82,84)$ and the airways (74). The exact contribution of each pathway is difficult to estimate. In the past, the lymphatics were considered the main pathway for clearance (18), but in reality, they drain only approximately $11 \%$ of edema fluid in newborn lambs (81) and only 8.8 to $14.6 \%$ of hydrostatic edema fluid in adult anesthetized sheep (80). The principal pathway for resorption of interstitial edema seems to be the circulation, that rapidly clears the protein-free lung liquid in newborn lambs (81) and may also account for the prompt recovery from interstitial edema when vascular pressure drops after edema induced by a sudden elevation in microvascular pressure (18). As dictated by Starling's equation, as microvascular hydrostatic pressure falls, the relatively low interstitial osmotic pressure compared with microvascular osmotic pressure favors reabsorption of edema fluid into the circulation. In anesthetized sheep and newborn lambs, 80 to $90 \%$ of crystalloids and water are cleared by the pulmonary circulation $(67,81)$. Recently Pearse et al (82) found in isolated sheep lungs that $42 \%$ of edema was reabsorbed in the pulmonary vasculature. Wickerts et al (84) showed that furosemide given to dogs with hydrostatic pulmonary edema increased water clearance, probably via the pulmonary circulation, due to its effect of increasing plasma colloid osmotic pressure. Jary and Matthay (83) showed that the bronchial circulation, in the absence of pulmonary blood flow, cleared approximately $50 \%$ of interstitial edema fluid in sheep.

Recently, the pleural space has also been found to be important in clearing fluid from the lung. There is normally a small hydrostatic pressure gradient from the subpleural interstitial 
tissue to the pleural space, but in pulmonary edema, it rises sufficiently to create a net driving pressure into the pleural space (36). Patients with congestive heart failure, whose pulmonary vascular wedge pressure exceeds $20 \mathrm{~mm} \mathrm{Hg}$, have readily detectable pleural effusions (85). In hydrostatic pulmonary edema in anesthetized sheep, Broaddus et al (86) estimated that $23-29 \%$ of all edema fluid was cleared by the pleural space.

The pathway most recently proposed for the clearance of interstitial edema is along the loose peribronchovascular connective tissue to the mediastinum following the route taken by air in interstitial emphysema (18). Staub et al (21) and Michel et al (42) studying the morphology of edema, noted large peribronchovascular liquid cuffs in the loose connective tissue extending to the hilum of the lung, so that this is a potential route of clearance, albeit unproven.

\section{Role of ventilation in treatment and clearance of lung edema}

In the clinical setting, to treat pulmonary edema in its critical phase of alveolar flooding, $\mathrm{FiO}_{2}$ is increased and mechanical ventilation with PEEP (positive end-expiratory pressure) is instituted $(87,88)$. There is general agreement that mechanical ventilation with PEEP is beneficial in treating hypoxemia in experimental and clinical pulmonary edema. The theory behind the use of ventilation in pulmonary edema is that ventilation, by increasing the transepithelial hydrostatic gradient, could clear alveolar edema and thereby improve oxygenation $(29,89)$. PEEP has beneficial effects on lung mechanics and gas exchange by increasing functional residual capacity, which results in the ventilation of previously unventilated lung units (90). Alternatively, PEEP could redistribute pulmonary edema fluid 
from the alveolar spaces to the alveolar interstitium and to the extraalveolar peribronchovascular interstitial space $(90,91)$.

However, the effects of PEEP on lung water and on lung water clearance are controversial. In normal lungs, $Q w 1 / d Q l$ may be increased when PEEP is applied as shown by Frostell et al $(92,93)$ who found that dogs ventilated with PEEP had an increased Qwl/dQ1 compared to dogs ventilated with ZEEP (zero end-expiratory pressure), whose Qwl/dQI remained normal. In experimentally induced hydrostatic pulmonary edema, PEEP has been found to have variable effects: on one hand, there are studies reporting that $Q w 1 / d Q 1$ is the same whether PEEP or ZEEP are used $(94,95)$. Blomqvist et al (96) on the other hand, reported that ventilation with PEEP during the resolution phase following experimental hydrostatic pulmonary edema reduced the rate of edema clearance from the lung compared to ventilation with ZEEP. Similar findings were reported by Demling et al (97). There are several possible explanations for the finding that PEEP may hinder edema clearance. Demling et al (97), Frostell et al $(92,93)$ and Skaburskis et al $(98)$ consider that the increased lung volume with PEEP decreases the fluid pressure in the extra-alveolar perimicrovascular interstitial space, thereby increasing fluid filtration. It is also possible, through recruitment of previously atelectatic alveoli, that the surface area available for transudation increases (98). It also seems that PEEP may obstruct pulmonary lymph flow, and impede edema clearance (93).

The role of ventilation in the clearance of edema from the alveoli is also controversial: indeed, Matthay et al $(67,68)$ and Berthiaume et al $(99)$ found the same rate of alveolar liquid clearance, whether they were ventilated with PEEP or were breathing spontaneously, 
and concluded that ventilation is not important in the movement of fluid from the alveoli to the interstitium. Pare et al (90) and Malo et al (91) in contrast showed that ventilation with PEEP produced a redistribution of fluid from the alveoli to the interstitium and that total lung water did not change.

Other related aspects of lung edema worthy of discussion here are its distributions along gravity-dependent gradients and the effect of ventilation on these gradients. Although it is widely believed that pulmonary edema, particularly hydrostatic edema, is distributed along gravity-dependent gradients, this remains a controversial issue. For example, Coates et al (100) and Hedlund et al (101) showed with CT scanning that hydrostatic pulmonary edema tends to accumulate in the hilar and dependent regions of the lung. The problem with CT scanning and several other radiographic techniques is that the increased density that is observed is not necessarily due only to increased extravascular water but may also be due to increased blood volume or to atelectasis. Since the aforementioned authors $(100,101)$ did rot measure regional extravascular lung water or blood content, therefore, it is difficult to attribute with certainty the gravity-dependent gradient observed with CT to a gradient in edema. Schober et al (102), however, measured regional extravascular lung water and blood volume with position emission tomography in 5 controls and 14 patients with congestive heart failure and found in the latter group a gradient of extravascular lung water with more edema in the dependent regions but a flat distribution in the blood content. Their results contrast with those of Tsang et al (103) who found no significant gravity-dependent gradients of lung water in either hydrostatic or increased permeability ederna. 
There is very little information in the literature on the role of ventilation on gravitydependent gradients of edema, since virtually all studies have been done in ventilated or spontaneously breathing lungs. One group of studies, however, is relevant. Indeed, Gattinoni et al (104) studied ten patients with acute respiratory failure using CT scanning: when the patients were in the supine position, CT density increased and regional inflation fell from ventral to dorsal; when they were scanned in the prone position, the gradients were reversed, consistent with the notion that the redistribution in gradients was due to a redistribution of intrapulmonary gas. The authors also suggested that the increased CT density in the dependent regions was due to compression atelectasis, that was prevented by the application of PEEP (105).

In summary, there are controversies which remain unresolved on the role of ventilation in the clearance and distribution of lung edema in general, and of alveolar edema in particular. Furthermore, the role of ventilation in maintaining and modulating gravity-dependent gradients of CT density and of extravascular lung water are unknown. In the clinicallyrelevant studies using $\mathrm{Ci}$ alone to measure lung density in acute respiratory failure, the mechanism for these changes in density must be ascertained, since they could be due to extravascular lung water, to atelectasis or to alterations in blood content.

To address some of these problems, the present study was undertaken.

\section{Hypothesis}

Pulmonary edema is an important clinical condition whose mortality is related to alveolar flooding that produces shunting and ventilation/perfusion imbalance and alters gas exchange, 
resulting in hypoxernia, hypercarbia and acidosis. The current treatment of lung edema revolves around ventilation, usually with PEEP. Ventilation may act in the therapy of alveolar edema in two ways: first, by opening previously collapsed alveoli and distributing the edema over a wider surface area; second, by promoting the clearance of alveolar edema into the interstitium and potentially out of the lung altogether.

In the present study, we hypothesized that ventilation may act by both of these mechanisms compared with unventilated lungs, a question which has not been exannined in detail. The study was clinically relevant since we employed CT scanning on one hand, and since we made regional measurements of extravascular lung water, blood content and atelectasis, to ascertain the cause of the increased CT density on the other.

\section{Objectives}

The general aim was to ascertain the influence of ventilation of variable durations on a lung model of alveolar edema induced by instillation through the airways of a proteincontaining solution.

The specific objectives were to:

1) Determine the effect of ventilation of the left lower lobe on regional CT density, specifically gravity-dependent, compared with the unventilated right lower lobe.

2) Establish whether any observed changes in CT density with ventilation are due to alterations in extravascular lung water, blood content, or atelectasis.

3) Ascertain whether ventilation accelerates the clearance of lung edema compared with unventilated lungs. 
4) Determine with light microscopy whether ventilation promotes the movement of fluid from the alveoli into the interstitium.

\section{Rationale}

Virtually all studies of the clearance of lung edema are in spontaneously breathing animals or in ventilated animals. Indeed, most have compared the benefits or drawbacks of lungs ventilated with PEEP versus those with ZEEP, or of ventilated versus spontaneously breathing animals. In our model, we wished to compare the distribution and clearance of alveolar edema in ventilated versus completely unventilated lungs, eliminating some of the inter-animal variation and permitting a reduction in the number of experiments to be performed.

The instillate to produce the alveolar edema had a protein concentration of $5 \%$ to ensure that it could be detected by light microscopy.

CT scanning was used to image the lobes after the ventilation period because it is a technique used frequently in patients to assess lung density changes in general, and edema in particular; its resolution is distinctly superior to that of conventional chest roentgenograms. In addition, however, as indicated above, the factors responsible for the observed changes in CT density, ie. atelectasis, extravascular lung water and blood content, were determined by specific analyses and measurements, and enabled us to map out gravity-dependent gradients for each of them. 


\section{REFERENCES}

1. Milne ENC, Pistolesi M. Pulmonary edema. Cardiac and non-cardiac. In: Lenfant C. ed. Lung Biology in Health and Disease. Diagnostic imaging of the lung. New York: Marcel Dekker, vol. 46, 1990; 235-336.

2. Fedullo AJ, Swinburne AJ, Wahl GW, Bixby K. Acute cardiogenic pulmonary edema treated with mechanical ventilation. Factors determing in-hospital mortality. Chest 1991; 99:1220-1226.

3. Matthay MA. Resolution of pulmonary edema. New insights. West J Med 1991; $154: 315-321$.

4. Andreadis N, Petty TL. Adult respiratory distress syndrome: problems and progress. Am Rev Resp Dis 1985; 132:1344-1346.

5. Demling RH. Current concepts on the adult respiratory distress syndrome. Circulatory Shock 1990; 30:297-309.

6. Lewis JF, Jobe AH. Surfactant and the adult respiratory distress syndrome. Am Rev Respir Dis 1993; 147:218-233.

7. Casaburi R, Wasserman K, Effros RM. Detection and measurement of pulmonary edema. In: Staub NC. ed. Lung Water and Solute Exchange. New York: Marcel Dekker, vol. 7, 1978; 323-376.

8. Staub NC. Pulmonary edema. Physiol Rev 1974 ; 54:678-811.

9. Landis EM, Pappenheimer JR. Exchange of substances through the capillary walls. In: Hamilton WF. ed. Handbook of Physiology. Circulation. Washington, DC: Am Physiol Soc, sect. 2, vol. II, 1963; 961-1034. 
10. Michel RP, Inoue S, Hogg JC. Pulmonary capillary permeability to HRP in dogs: a physiological and morphological study. J Appl Physiol 1977; 42:13-21.

11. Taylor AE. Capillary fluid filtration. Starling forces and lymph flow. Circ Res 1981; 49:557-575.

12. Crandall ED. Water and nonelectrolyte transport across alveolar epithelium. Am Rev Resp Dis 1983; 127:S16-S24.

13. Staub NC. "State of Art" Review. Pathogenesis of pulmonary edema. Am Rev Resp Dis 1974; 109:358-372.

14. Staub NC. Pulmonary edema. Physiologic approaches to management. Chest 1978; 74:559-564.

15. Renkin EM. Some consequences of capillary permeability to macromolecules. Starling's hypothesis reconsidered. Am J Physiol 1986; 250:H706-H710.

16. Vreim CE, Snashall PD, Demling RH, Staub NC. Lung lymph and free interstitial fluid protein composition in sheep with edema. Am J Physiol 1976; 230:1650-1653.

17. Vreim CE, Snashall PD, Staub NC. Protein composition of lung fluids in anesthetized dogs with acute cardiogenic edema. Am J Physiol 1976; 231:1466-1469.

18. Staub NC. New concept about the pathophysiology of pulmonary edema. J Thorac Imag 1988; 3:8-14.

19. Staub NC. Pathways for fluid and solute fluxes in pulmonary edema. In: Fishman AP, Renkin EM. eds. Pulmonary Edema. Bethesda, MD: Am Physiol Soc, 1979; 113124. 
20. Staub NC, Gee MH, Vreim CE. Mechanism of alveolar flooding in acute pulmonary edema. In: Porte R, O'Connor M. ed. Lung Liquids, Amsterdam: Elsevier 1976; p.255-272.

21. Staub NC, Nagano H, Pearce ML. Pulmonary edema in dogs, especially the sequence of fluid accumulation in lungs. J Appl Physiol 1967; 22:227-240.

22. Backmann R, Hartung W. Measurement of blood volume in the lung. Prog Resp Res 1966; 5:327-333.

23. Cook CD, Mead J, Schreiner GL, Frank NR, Craig JM. Pulmonary mechanics during induced pulmonary edema in anesthetized dogs. J Appl Physiol 1959; 14:177-186.

24. Noble WH, Kay JC, Obdrzalek J. Lung mechanics in hypervolemic pulmonary edema. J Appl Physiol 1975; 38:681-687.

25. Matthay MA, Matthay RA. Pulmonary edema: Cardiogenic and Noncardiogenic. In: George RB, Light RW, Matthay MA et al eds. Chest Medicine. Baltimore, MD: William \& Wilkins 1990;439-453.

26. Drake RE, Allen SJ, Williams JP, Laine GA, Gabel JC. Lymph flow from edematous dog lungs. J Appl Physiol 1987; 62:2416-2420.

27. Havill $\mathbf{A M}$, Gee $\mathrm{MH}$. Resolution of increased permeability pulmonary edema in rats. Am J Pathol 1987; 127:441-446.

28. Mitzner W, Sylvester JT. Lymph flow and lung weight in isolated sheep lungs. J Appl Physiol 1986; 61:1830-1835.

29. Staub NC. Alveolar flooding and clearance. Am Rev Respir Dis 1983; 127:S44-S51. 
30. Michel RP. Lung microvascular permeability to dextran in $\alpha$-naphthylthiourea-induced edema. Am J Pathol 1985;119:474-484

31. Iliff LD. Extra-alveolar vessels and edema development in excised dog lungs. Circ Res 1971; 28:524-532.

32. Lai-Fook SJ, Toporoff B. Pressure-volume behavior of perivascular interstitium measured in isolated dog lung. J Appl Physiol 1980; 48:939-946.

33. Parker JC, Falgout HJ, Grimbert FA, Taylor AE. The effect of increased vascular pressure on albumin excluded volume and lymph flow in the dog lung. Circ Res 1980; 47:866-875.

34. Snashall PD, Weidner WJ, Staub NC. Extravascular lung water after extracellular fluid volume expansion in dogs. J Appl Physiol 1977; 42:624-629.

35. Snashall PD. Pulmonary oedema. Br J Dis Chest 1980; 74:2-10.

36. Bhattacharya J, Gropper MA, Staub NC. Interstitial fluid pressure gradient measured by micropuncture in excised dog lung. J Appl Physiol 1984; 56:271-277.

37. Gee MH, Williams DO. Effect of lung inflation on perivascular cuff fluid volume in isolated dog lung lobes. Microvasc Res 1979; 17:192-201.

38. Conhaim RL, Gropper MA, Staub NC. Effect of lung inflation on alveolar-airway barrier protein permeability in dog lung. J Appl Physiol 1983; 55:1249-1256.

39. Conhaim RL, Lai-Fook SJ, Staub NC. Sequence of perivascular liquid accumulation in liquid-inflated dog lung lobes. J Appl Physiol 1986; 60:513-520.

40. Conhaim RL. Growth rate of perivascular cuffs in liquid-inflated dog lung lobes. J Appl Physiol 1986; 61:647-653. 
41. Unruh HW, Goldenberg HS, Oppenheimer L. Pulmonary interstitial compartments and tissue resistance to fluid flux. J Appl Physiol 1984; 57:1512-1519.

42. Michel RP, Meterissian S, Poulsen RS. Morphometry of the distribution of hydrostatic pulmonary oedema in dogs. Br J Exp Path 1986; 67:865-877.

43. Michel RP, Hakim TS, Smith TT, Poulsen RS. Quantitative morphology of permeability lung edema in dogs induced by alpha-naphthylthiourea. Lab Invest 1983; 49:412-419.

44. Michel RP, Smith TT, Poulsen RS. Distribution of fluid in bronchovascular bundles with permeability lung edema induced by alpha-naphthylthiourea in dogs: A morphometric study. Lab Invest 1984; 51:97-103.

45. Cottrell TS, Levine OR, Senior RM, Wiener J, Spiro D, Fishman AP. Electron microscopic alterations at the alveolar level in pulmonary edema. Circ Res 1967; 21:783-797.

46. Szidon JP, Pietra GG, Fishman AP. The alveolar-capillary membrane and pulmonary edema. N Eng J Med 1972; 286: 1200-1208.

47. DeFouw DO. Morphologic study of the alveolar septa in normal and edematous isolated dog lungs fixed by vascular perfusion. Lab Invest 1980; 42:413-419.

48. Bachofen $\mathbf{M}$, Bachofen $\mathbf{H}$, Weibel ER. Lung edema in the adult respiratory distress syndrome. In: Fishman AP, Renkin EM. ed. Pulmonary Edema. Bethesda, MD: Am Physiol Soc 1979; 241-252. 
49. Taylor AE, Parker JC. Pulmonary interstitial spaces and lymphatics. In: Fishman AP. a. Handbook of Physiology. Sect. 3. The Respiratory System. Vol. 1. Circulation and Nonrespiratory Functions. Bethesda, MD: Am Physiol Soc 1985; 167-230.

50. Ingram RH, Braunwald E. Pulmonary edema: Cardiogenic and Noncardiogenic. In: Braunwald E. ed. Heart disease. Philadelphia: W.B. Saunders Company, 1988; 471484.

51. Braunwald E. Edema. In: Wilson JD, Braunwald $\mathrm{E}$, Isselbacher $\mathrm{KJ}$ et al. eds. Harrison's principles of Internal Medicine. New York: McGraw-Hill, 1991; 228-231.

52. Yoneda K. Anatomic pathway of fluid leakage in fluid-overload pulmonary edema in mice. A.m J Pathol 1980; 101:7-16.

53. Chemiack RM, Crystal RG, Kalica AR. Current concepts in idioparhic pulmonary fibrosis: a road map for the future. Am Rev Respir Dis 1991; 143:680-683.

54. Brody AR, Soler P, Basset VF, Haschek WM, Witschi H. Epithelial-mesenchymal associations of cells in human pulmonary fibrosis and in BHT-oxygen-induced fibrosis in mice. Exp Lung Res 1981; 2:207-220.

55. Conhaim RL. Airway level at which edema liquid enters the air space of isolated dog lung. J Appl Physiol 1989; 67:2334-2342.

56. Zumsteg TA, Havili AM, Gee MH. Relationship among lung extra-vascular fluid compartments with alveolar flooding. J Appl Physiol 1982; 53:267-271.

57. Vassilyadi $\mathbf{M}$, Michel RP. Pattern of fluid accumulation in $\mathrm{NO}_{2}$-induced pulmonary edema in dogs. A morphometric study. Am J Pathol 1988; 130:10-21. 
58. Malo J, Ali J, Wood LDH. How does positive end-expiratory pressure reduce intrapulmonary shunt in canine pulmonary edema? J Appl Physiol 1984; 57:1002-1010.

59. Montaner JSG, Tsang J, Hogg JC. Alveolar epithelial damage: A critical difference between high pressure and oleic acid-induced low pressure pulmonary edema. J Clin Invest 1986; 77:1786-1796.

60. Bachofen H, Schürch S, Michel RP, Weibel ER. Experimental hydrostatic pulmonary edema in rabbit lungs. Morphology. Am Rev Respir Dis 1993; 147:989-996.

61. Bachofen H, Schurch S, Weibel ER. Experimental hydrostatic pulmonary edema in rabbit lungs. Barrier lesions. Am Rev Respir Dis 1993; 147:997-1004

62. Noble WH. Pulmonary oedema: a review. Can Anaesth Soc J 1980; 27:286-302.

63. Bongard F, Matthay MA, Mackeasie RC. Morphologic and physiologic correlates of increased extravascular lung water. Surgery 1984; 96:395-403.

64. Havill AM, Gee MH. Role of interstitium in clearance of alveolar fluid in normal and injured lungs. J Appl Physiol 1984; 57:1-6.

65. Pietra GG. New insights into mechanisms of pulmonary edema. J Clin Invest 1984; $51: 489-494$.

66. Egan EA. Effect of lung inflation on alveolar permeability to solutes. Ciba Symp 1976; 38:101-114.

67. Matthay MA, Landolt CC, Staub NC. Differential liquid and protein clearance from the alveoli of anesthetized sheep. J Appl Physiol 1982; 53:96-104. 
68. Matthay MA, Berthiaume Y, Staub NC. Long-term clearance of liquid and protein from the lungs of unanesthetized sheep. J Appl Physiol 1985; 59:928-934.

69. O'Brodovich H. Epithelial ion transport in the fetal and perinatal lung. Am J Physiol 1991; 261:C555-C564.

70. Effros RM, Mason GR, Hukkanen J, Silverman P. New evidence for active sodium transport from fluid-filled rat lungs. J Appl Physiol 1989; 66:906-919.

71. Welsh M. Electrolyte transport by airway epithelium. Physiol Rev 1987; 67:11431187.

72. Crandall ED, Heming TA, Palombo RL, Goodman BE. Effects of terbutaline on sodium transport in isolated perfused rat lung. J Appl Physiol 1986; 60:289294.

73. Berthiaume Y, Staub NC, Matthay NA. Beta-adrenergic agonists increase lung liquid clearance in anesthetized sheep. J Clin Invest 1987; 79:335-343.

74. Matthay MA. Resolution of pulmonary edema. Mechanism of liquid, protein, and cellular clearance from the lung. Clin Chest Med 1985; 6:521-545.

75. Berthiaume Y, Albertine HK, Grady M, Fick G, Matthay MA. Protein clearance from the air spaces and lungs of unanesthetized sheep over 144 h. J Appl Physiol 1989; 67:1887-1897.

76. Bignon J, Jaurand MC, Pinchon MC, Sapin C, Warnet JM. Immunoelectron microscopic and immunochemical demonstrations of serum proteins in the alveolar lining material of the rat lung. Am Rev Resp Dis 1976; 113:109-120.

77. Kim KJ, Lebon TR, Shinbane JS, Crandall ED. Asymmetric $\left[{ }^{14} \mathrm{C}\right]$ albumin transporc across bullfrog alveolar epithelium. J Appl Physiol 1985; 59:1290-1297. 
78. Matthay MA, Grady M, Serikov V. Effect of hypothermia $\left(7^{\circ} \mathrm{C}\right)$ on alveolar protein clearance in isolated goat lungs. (Abstract) FASEB J 1990; 2340.

79. Taylor AE. The lymphatic edema safety factor. The role of edema dependent lymphatic factors (EDLF). Lymphology 1990; 23:111-123.

80. Mackersie RC, Christensen J, Lewis FR. The role of pulmonary lymphatics in the clearance of hydrostatic pulnionary ederia. J Surg Res 1987; 43:495-504.

81. Bland RD, Hansen TN, Haberkern CM, Bressack TA, Hayinski J, Raj JU, Goldberg RB. Lung fluid balance in lambs before and after birth. J Appl Physiol 1982; 53:9921004.

82. Pearse DB, Wagner EM, Sylvester JT. Edema clearance in isolated sheep lungs. J Appl Physiol 1993; 74:126-132.

83. Jayr C, Maithay MA. Alveolar and lung liquid clearance in the absence of pulmonary blood flow in sheep. J Appl Physiol 1991; 71:1679-1687.

84. Wickerts CJ, Blomqvist H, Berg B, Rosblad PG, Hedenstierna G. Furosemide, when used in combination with positive end-expiratory pressure, facilitates the resorption of extravascular lung water in experimental hydrostatic pulmonary edema. Acta Anesthesiol Scand 1991; 35:776-783.

85. Wiener-Kronish JP, Matthay MA, Callen PW, Filly RA, Gamsu G, Staub NC. Relationship of pleural effusions to pulmonary hemodynamics in patients with congestive heart failure. Am Rev Respir Dis 1985; 132:1253-1256. 
86. Broaddus VC, Wiener-Kronish JP, Staub NC. Clearance of lung edema into the pleural space of volume-loaded anesthetized sheep. J Appl Physiol 1990; 68:26232630.

87. Matthay MA, Wiener-Kronish JP. Intact epithelial barrier function is critical for the resolution of alveolar edema in humans. Am Rev Respir Dis 1990; 142:1250-1257.

88. Bersten AD, Holt AW, Vedig AE, Skowronski GA, Baggoley CJ. Treatment of severe cardiogenic pulmonary edema with continuous positive airway pressure delivered by face mask. N Engl J Med 1991; 325:1825-1830.

89. Muir AL, Hall DL, Despas P, Hogg JC. Distribution of blood flow in the lungs in acute pulmonary edema in dogs. J Appl Physiol 1972; 33:763-769.

90. Pare PD, Warriner B, Baile EM, Hogg JC. Redistribution of pulmonary extravascular water with positive end-expiratory pressure in canine pulmonary edema. Am Rev Resp Dis $1983 ; 127: 590-593$.

91. Malo J, Ali J, Wood LDH. How does positive end-expiratory pressure reduce intrapulmonary shunt in canine pulmonary edema? J Appl Physiol 1984; 57:1002-1010.

92. Frostell C, Blomqvist CJ, Hedenstierna G. Lung fluid balance evaluated by the rate of change of extravascular lung water content. Acta Anesthesiol Scan 1990; 34:362-369.

93. Frostell C, Blomqvist H, Wickerts CJ. Effects of PEEP on extravascular lung water and central blood volume in the dog. Acta Anesthesiol Scand 1987; 31:711-716. 
94. Bredenberg CE, Kazui T, Webb WR. Experimental pulmonary edema: The effect of positive end-expiratory pressure on lung water. Ann Thorac Surg 1978; 26:62-67.

95. Hopewell PC, Murray JF. Effect of continuous positive-pressure ventilation in experimental pulmonary edema. J Appl Physiol 1976; 40:568-574.

96. Blomqvist H, Wickerts CJ, Berg B, Frostell C, Jolin A, Hedenstierna G. Does PEEP facilitate the resolution of extravascular lung water after experimental hydrostatic pulmonary edema? Eur Respir J 1991; 4:1053-1059.

97. Demling RH, Staub NC, Edmunds HL. Effect of end-expiratory airway pressure on accumulation of extravascular lung water. J Appl Physiol 1975; 38:907-912.

98. Skaburskis M, Michel RP, Gatensby A, Zidulka A. Effect of negative-pressure ventilation on lung water in permeability pulmonary edema. J Appl Physiol 1989; 66:2223-2230.

99. Berthiaume Y, Broaddus VC, Gropper MA, Tanita T, Matthay MA. Alveolar liquid and protein clearance from normal dog lungs. J Appl Physiol 1988; 65:585-593.

100. Coates G, Powels P, Morrison AC. The effect of intravenous infusion of saline on lung density, lung volumes, nitrogen washout, computed tomographic scans and chest radiographs in humans. Am Rev Respir Dis 1983; 127:91-99.

101. Hedlund LW, Vock P, Effmann EL, Lischko MM, Putman CE. Hydrostatic pulmonary edema. An analysis of lung density changes by computed tomography. Invest Radiol 1984; 19:254-262. 
102. Schober $\mathrm{OH}$, Meyer GJ, Bossaller C, Creutzig H, Lichtlen PR, Hundeshagen H. Quantitative determination of regional extravascular lung water and regional blood volume in congestive heart failure. Eur J Nucl Med 1985; 10:17-24.

103. Tsang JY, Baile EM, Hogg JC. Relationship between regional pulmonary edema and blood flow. J Appl Physiol 1986; 60:449-457.

104. Gattinoni L, D'Andrea L, Pelosi P, Vitale G, Pesenti A, Fumagalli R. Regional effects and mechanism of positive end-expiratory pressure in early adult respiratory distress syndrome. JAMA 1993; 269:2122-2127.

105. Gattinoni L, Pelosi P, Vitale G, Pesenti A, D'Andrea L, Mascheroni D. Body position chinges redistribute lung computed tomographic density in patients with acute respiratory failure. Anesthesiology 1991;74:15-23. 


\title{
CHAPTER 2
}

\section{DISTRIBUTION OF ALVEOLAR EDEMA IN VENTILATED}

\author{
AND UNVENTILATED CANINE LUNG LOBES
}




\begin{abstract}
RATIONALE AND OBJECTIVES. Ventilation is frequently used in the treatment of cardiogenic and increased permeability pulmonary edema. The effects of ventilation on the distribution of pulmonary edema, including on gravity-dependent gradients, as determined by computed tomography (CT) scanning, are unclear. To address this problem, we studied the effects of ventilation on a canine model of alveolar edema with CT scanning and related the changes in density to measurements of regional extravascular lung water ( $Q$ wl/dQl) and blood content. We also examined its distribution in the alveoli and pulmonary interstitium with light microscopy.
\end{abstract}

METHODS. Alveolar edema was induced in 16 supine dogs $(18.2 \pm 1.6 \mathrm{~kg})$ by instillation of $30-50 \mathrm{ml} 5 \%$ albumin in $6 \%$ dextran-75 through the airways of each lower lobe using a double lumen tracheal tube. The dogs were ventilated, only on the left side, for $1 \min (n=4), 30 \min (n=6)$ or $60 \min (n=6)$. The lower lobes were excised, frozen in liquid nitrogen, and imaged in a CT scanner. Regions of interest (ROI) were outlined on the apical, middle and basal CT slices and tissue sections from corresponding regions were taken for measurements of Qwl/dQl, blood content, and for histology, to grade semiquantitatively interstitial and alveolar edema.

RESULTS. There was a significant fall in the CT density of the left lower lobes compared with the right lower lobes in the 30 and in the $60 \mathrm{~min}$ ventilation groups $(\mathrm{P}<$ 0.05). The gravity-dependent gradients of CT density were unaffected by ventilation. There were no significant differences in $\mathrm{Qwl} / \mathrm{dQ}$ between right unventilated and left ventilated lungs in any of the three groups but there was a gravity-dependent gradient of Qwl/dQ1. The 
histological grading showed a trend $(P=0.054)$ for more interstitial edema in the left lower lobes in the group ventilated for $60 \mathrm{~min}$ compared with the group ventilated for $1 \mathrm{~min}$.

CONCLUSIONS. These data show that in our model of instilled alveolar odema, ventilation acts primarily by increasing aeration and that it plays a minor role in moving fluid to the interstitium. The data also emphasize the importance of regional lung water and blood measurements and of histology in determining the causes of alterations in CT density.

KEY WORDS: pulmonary edema, ventilation, CT scanning, edema clearance, extravascular lung water. 


\section{INTRODUCTION}

Pulmonary edema, defined as an increase in extravascular lung water, may be divided, on the basis of Starling's equation into two principal forms (1). The first, hydrostatic edema, develops because of elevated microvascular pressure in the lung, usually due to left-sided heart failure and is characterizei by an intact alveolocapillary barrier and a relatively low protein content $(2,3)$. The second, increased permeability edema, occurs in infections, drug overdose and in the adult respiratory distress syndrome, is characterized by damage to the alveolocapillary barrier and the edema fluid has a high protein content (4-8). Mortality in both of these forms of pulmonary edema is related largely to alveolar flooding that disrupts gas exchange and causes shunting with hypoxemia, acidosis and hypercapnia $(9,10)$. There has been much interest recently, not only in the mechanisms of alveolar flooding, but also on the time course, pathways and mechanisms of its clearance. There are two major obstacles to the clearance of fluid from the alveoli: first, the alveolar epithelium itself that has, at least in hydrostatic edema, tight intercellular junctions (11-13) and second, the osmotic pressure generated by the proteins in the alveoli (14). The clearance rates across the alveolar epithelium are more rapid for crystalloids and water than for proteins $(13,15)$ and the mechanisms of clearance differ for each of these: indeed sodium is cleared by active transport, whereas proteins are removed by transcytosis, and water follows passively $(2,14-$ 18). Once the alveolar edema fluid reaches the interstitium, there are several pathways or potential pathways for the clearance of interstitial edema, including the lymphatics $(19,20)$, 
the pulmonary and bronchial circulations $(18,21-23)$, the mediastinum $(18,22)$, the pleural space $(22,24)$ and the airways $(25)$.

In the treatment of pulmonary edema, in the critical alveolar flooding phase, $\mathrm{FiO}_{2}$ is increased and mechanical ventilation with positive end-expiratory pressure (PEEP) is instituted (26-28). Ventilation is believed to clear the alveolar edema by increasing the transepithelial hydrostatic gradient. This mechanism, however, is controversial since ventilation may act on gas exchange and alveolar edema in two distinct, but not necessarily mutually exclusive phases (14). First, it may open collapsed alveoli and distribute the fluid over a larger surface; second, ventilation could clear fluid by displacing it into the interstitium. The studies of Pare et al (29) and Malo et al (30) support the latter mechanism, whereas Matthay et al $(13,15)$ and Berthiaume et al $(31)$ suggest that ventilation has little effect on the movement of fluid from the alveoli to the interstitium. According to Blomqvist et al (32) and Wickerts et al (33), ventilation with PEEP improves oxygenation, but does not facilitate the clearance of lung edema.

Another potential effect of ventilation is on the gravity-dependent distribution of edema. Indeed, several studies have described, using CT scanning and other techniques, that edema is distributed along gravity-dependent gradients (34-36). The specific role of ventilation in establishing or altering these gravity-dependent gradients, however, is unknown. Furthermore, the relative contribution of regional edema, blcod content and atelectasis to the gradients demonstrated by CT scanning is unclear. Gattinoni et al $(37,38)$ found, in patients with the ARDS, that PEEP prevented atelectasis in the dependent regions of the lung. They could not, however, directly relate their Cr density values to 
measurements of extravascular lung water. In the present study, therefore, we wished to examine the effects of ventilation for different time periods on alveolar edema, using CT scanning, and to relate these findings to measurements of extravascular lung water and regional blood volume and to light microscopic grading of interstitial and alveolar edema and of atelectasis.

\section{MATERIALS AND METHODS}

\section{Preparation and physiological measurements:}

A total of 16 adult mongrel dogs of either sex weighing $18.2 \pm 1.6 \mathrm{~kg}$ (SE), free of respiratory or other diseases, were studied. Thev were anesthetized with sodium pentobarbital intravenously $(25 \mathrm{mg} / \mathrm{kg}$ ), placed in the supine position, intubated and left to breathe room air spontaneously. Anesthesia was maintained with regular doses of $65 \mathrm{mg}$ pentobarbital. A tracheostomy was performed to introduce an endotracheal tube. Through femr.ai cutdowns, we placed three catheters: a Swan-Ganz catheter through one vein to measure pulmonary arterial (Ppa) and pulmonary arterial wedge (Ppaw) pressures; a catheter in the femoral artery to measure systemic arterial pressure (Psys) and one in the other femoral vein for intravenous fluid and drug administration. The catheters were flushed regularly with heparinized saline. All pressures were recorded on an eight-channel HewlettPackard recorder, model 7758 A (Hewlett-Packard, Waltham, MA). Cardiac output ( $\left.\dot{\mathrm{Q}}_{\mathrm{T}}\right)$ was measured by the thermodilution principle with a cardiac output computer, model 9510 (American Edwards Laboratories, Santa Ana, CA). Pulmonary vascular resistance (PVR) 
was calculated with the formula PVR $=($ Ppa-Ppaw $) / \dot{Q}_{r}$. In addition, systemic arterial blood $\mathrm{PO}_{2}, \mathrm{PCO}_{2}$ and $\mathrm{pH}$ were measured using a blood gas analyzer, model AVL 939 (Roxon Medi-Tech., Montreal, QC) as per the protocol below.

\section{Instillation of fluid and protocol}

Pre-edema, baseline measurements of Ppa, Ppaw, Psys, $\dot{\mathrm{Q}}_{\mathrm{T}}$ and arterial blood $\mathrm{PO}_{2}$, $\mathrm{PCO}_{2}$ and $\mathrm{pH}$ were made. Then we removed the endotracheal tube and we replaced it with a double lumen divided tracheal tube (Willy Rusch AG, Waiblingen, Germany) to ventilate the left lung only, the right lung remaining unventilated. Under fluoroscopy, we introduced through each lumen of the divided tracheal tube a Swan-Ganz catheter going to the most dependent positions of the left and right lower lobes; we verified their positions and that they were at the same level by taking antero-posterior and lateral chest roentgenograms (Fig. 1). After paralysing the dogs with $20 \mathrm{mg}$ succinylcholine, we instilled $30-50 \mathrm{ml}$ of $5 \%$ albumin in 6\% dextran-75 (Abbott Laboratories, Montreal, QC) in each lower lobe; the osmolarity of the instillate, measured with an osmometer, model 3W2 (Advanced Instruments Inc., Needham Heights, MA) was $302 \mathrm{mOsm} / \mathrm{kg} \mathrm{H} \mathrm{H}_{2} \mathrm{O}$. We had intended to use the dextran-75 as a tracer, but could not for technical reasons.

The dogs were then ventilated only on the left side, and divided into three groups: four dogs were ventilated for $1 \mathrm{~min}$, six for $30 \mathrm{~min}$ and six for $60 \mathrm{~min}$, with room air at 1215 breaths $/ \mathrm{min}$ and with a tidal volume of $25 \mathrm{ml} / \mathrm{kg}$; end-expiratory pressure was zero. The right lung remained unventilated and we obstructed the right lumen of the tracheal tube with a glove and measured its airway pressure. Measurements of Psys, Ppa, Ppaw, $\dot{\mathbf{Q}}_{\mathrm{T}}$ and 
arterial blood gases were performed at the end of the ventilation period. Just prior to terminating the experiments, we injected $20 \mathrm{ml}$ of autologous blood intravenously into the animals, the erythrocytes of which were labelled with $100 \mu \mathrm{Ci}{ }^{51} \mathrm{Cr}$, to correct extravascular lung water $(\mathrm{Qwl} / \mathrm{dQl})$ measurements for blood water (see below). The animals were then euthanized with an overdose of intravenous pentobarbital followed by $\mathrm{KCl}$. The trachea was clamped to prevent collapse of the lungs and the chest opened. The right and left lower lobes were clamped at the hilum, excised at functional residual capacity, frozen in liquid nitrogen as previously described $(39,40)$ and stored in a $-70^{\circ} \mathrm{C}$ freezer prior to CT scanning. The right and left middle and upper lobes were also excised and sampled for Qw1/dQl measurements to make sure no instilled edema fluid had entered them.

\section{CT scanning procedure}

Imaging was performed using a Philips Tomoscan-CX CT scanner (Philips, Eindhonven, The Netherlands). To avoid cardiac artifacts, scan time was set at $2.8 \mathrm{sec}$ at $120 \mathrm{kV}$ and $150 \mathrm{~mA}$. A reconstruction algcrithm appropriate for tissue (incorporating a smoothing filter) was used for analysis. The scanner was calibrated before each experiment so that the density of air was -1000 Hounsfield units (HU) and of water $0 \mathrm{HU}$. We expressed our CT data in CTQ values instead of HU, in accordance with the studies of Hedlund et al $(35,36)$; for this, we used the formula: CTQ $=\mathrm{HU}+1000$, so that air had a density of 0 and water $1000 \mathrm{CTQ}$. We scanned the frozen lower lobes by placing them on a specially designed Plexiglas platform on the bottom of a styrofoam container containing liquid nitrogen. The lobes were positioned as if the dog was in the supine position, ie with 
the apex to base axis in the horizontal position, and they were sectioned with the CT scanner in a transverse direction. First, $5 \mathrm{~mm}$-thick transverse slices were obtained every $4 \mathrm{~mm}$ over the total length of the lobes for a total of $\sim 35$ per lobe. Second, approximately ten $2 \mathrm{~mm}$ thick transverse slices were obtained over the same length. The CT scan data were stored on magnetic tape and representative films were made.

\section{Analysis of the CT scans}

We used the $5 \mathrm{~mm}$-thick slices to measure lung tissue densities. We selected three transverse slices at apical, middle and basal levels (Fig. 2). The middle transverse slice was taken approximately in the middle of the apex-to-base length of the lower lobes. The apical slice was taken four slices ( $5 \mathrm{~mm}$ transverse) towards the apex, and the basal slice four slices towards the base of the lower lobes. On each of the three (apical, middle and basal) transverse slices, we outlined, using the CT trackball, three gravity-dependent regions of interest (ROI), ventral, mid-ventral and dorsal. The ventral and dorsal ROIs were chosen in the most ventral and dorsal regions of each slice. The mid-ventral ROI was placed at the halfway point between the ventral and dorsal ROIs. The ROIs were selected to avoid the hilum, pleura and airways and each had an area of $-35 \mathrm{~mm}^{2}$. We obtained a mean CTQ values for each of the three ROI regions, ventral, mid-ventral and dorsal from the apical, middle and basal $5 \mathrm{~mm}$ transverse slices, and compared the ventilated left lower lobes with the unventilated right lower lobes.

We also measured the volumes of the frozen lower lobes using the $2 \mathrm{~mm}$-thick transverse CT slices: their outer boundaries were traced with a CT trackball to obtain their 
areas and the volume of each lower lobe calculated by multiplying the mean area of the slices by the total length (apex-to-base) of the lobe (41).

\section{Regional extravascular lung water and blood measurements}

Measurements of extravascular lung water $(\mathrm{Qwl} / \mathrm{dQl})$ were made as described previously (42). Briefly, $20 \mathrm{ml}$ of blood in $10 \mathrm{ml}$ acid-citrate-dextrose were incubated with $100 \mu \mathrm{Ci}{ }^{51} \mathrm{Cr}$ for $30 \mathrm{~min}$. The reaction was stopped with $250 \mathrm{mg}$ ascorbic acid, the enythrucytes were washed twice and slowly reinjected into the dog 15 to $20 \mathrm{~min}$ before the end of the experiment to allow recirculation. When the frozen lower lobes were cut, five samples from each of the ventral and dorsal regions were placed in pre-weighed vials, dried in an oven $\left(60^{\circ} \mathrm{C}\right)$ to a constant weight, and re-weighed. The lung samples, as well as blood, plasma and packed red blood cells were counted for 10 min each in a Beckman Gamma 9000 Counting System (Beckman Instruments, Fullerton, CA) from which we calculated Qw1/dQ1. We also calculated the blood content, expressed in $\mathrm{g}$ blood/g dry lung for each sample.

Tissue processing and light microscopic semi-quantitative grading

After the CT scanning, the frozen lower lobes were cut with a band saw at the halfway point into ventral and dorsal regions. Each region was subsequently cut in five 1.0-1.5 $\mathrm{cm}$ thick slices, labelled $V_{1}$ to $V_{5}$ for ventral and $D_{1}$ to $D_{5}$ for the dorsal region (Fig. 3). From each of these ten lobar slices, we took one tissue section randomly for histology and for measurement of $\mathrm{Qwl} / \mathrm{dQl}$. The sections for histology were fixed in Camoy's solution (60\% ethanol, $30 \%$ chloroform, $10 \%$ acetic acid) at $-70^{\circ} \mathrm{C}$ for $48 \mathrm{~h}$, then transferred to $80 \%$ 
ethanol, 20\% chloroform ( 3 changes at $18 \mathrm{~h}$ interval), and to $100 \%$ ethanol ( 3 changes at 12 $h$ interval), all at $-70^{\circ} \mathrm{C}$. Then the tissues were gradually warmed to room temperature over $2 \mathrm{~h}$, processed using routine histological techniques and embedded in paraffin. From the blocks, $5 \mu \mathrm{m}$-thick sections were cut and stained with haematoxylin and eosin.

For the histological grading, we examined two slides from each region (ventral, midventral and dorsal) of each lower lobe of each animal, specifically $V_{1}, V_{2}$ for the ventral, $V_{5}, D_{1}$ for the midventral and $D_{4}, D_{5}$ for the dorsal region, corresponding to the ROI selected by CT scanning. First, we graded interstitial edema by estimating the amount of perivascular and airway wall edema on an arbitrary scale of 0 to 3,0 representing no interstitial edema and 3 the greatest amount of interstitial edema (43). A mean value was calculated for each of the regions of the lower lobes. Second, we graded alveolar edema by estimating the percentage of alveolar surface area occupied by edema in $10 \%$ increments, $0 \%$ representing no alveolar edema and $100 \%$ total alveolar edema. A mean value was also calculated for each of the regions of both lower lobes. Atelectasis was also graded in $10 \%$ increments using the criteria of Zidulka et al (44).

\section{Statistical analysis}

All values are presented as means \pm standard error (SE). Block analysis of variance was done using a proprietary software (Systat Inc., Evanston, IL). Student's paired $t$ test and the Tukey test were used as post-hoc tests. Differences were considered significant at $P<$ 0.05 , or exact $P$ values were reported. 


\section{RESULTS}

\section{Physiological parameters}

Table 1 presents the hemodynamic and arterial blood gas measurements. There were no significani differences in Psys, but there was a significant increase $(P<0.05)$ in Ppaw and Ppa as well as in PVR post-edema for the $60 \mathrm{~min}$ ventilation group. Arterial blood gas measurements after 30 and $60 \mathrm{~min}$ ventilation showed significant acidosis, hypoxemia and hypercapnia $(P<0.05)$. The airway pressures in the right side of the divided tracheal tube were $0 \mathrm{mmHg}$.

\section{CT scanning}

These results are in Figure 4. The main finding was a significant fall in ROI CTQ of the mid-ventral and dorsal regions of the left lower lobes in the 30 and 60 min ventilation groups compared with the right lower lobes. There was no significant difference in ROI CTQ between the ventilation groups. Representative scans are shown in Figure 5. When we examined the CT scans for gravity-dependent gradients, there were significant $(P<0.05)$ gradients in CTQ values from ventral to mid-ventral to dorsal for both right and left lungs of all three groups of animals and these gradients were unaffected by ventilation.

The results of the respective right and left lobar volumes, measured by CT on the 2 mm slices, were as follows: at $1 \mathrm{~min}, 136 \pm 19 \mathrm{ml}$ and $155 \pm 19 \mathrm{ml}$; at $30 \mathrm{~min}, 182 \pm 21$ $\mathrm{ml}$ and $205 \pm 15 \mathrm{ml}$; and at $60 \mathrm{~min}, 152 \pm 8 \mathrm{ml}$ and $205 \pm 18 \mathrm{ml}$. Only the latter group 
showed a statistically significant difference $(P<0.05)$ between the right and left lower lobes volumes.

\section{Regional extravascular lung water and blood measurements}

The data for the Qwl/dQ1 are in Figure 6. There were no significant differences statistically between right unventilated and left ventilated lungs in any of the three groups. There was, however, some evidence of gravity dependent : adients of Qwl/dQl: at $1 \mathrm{~min}$ ventilation (Fig. 6A), there were gradients $(P<0.05)$ from left ventral to mid-ventral and to dorsal regions; at $60 \mathrm{~min}$ ventilation, there were gradients only for the right lower lobes, from ventral to mid-ventral and to dorsal. No gradints were observed in the group ventilated for $30 \mathrm{~min}$.

The average Qwl/dQl data for all slices from right and left lower lobes are in Figure 7, and show no significant effect of the duration of ventilation. The mean Qwl/dQl of the left upper and middle lobes was $3.55 \pm 0.16 \mathrm{~g} \mathrm{H}_{2} \mathrm{O} / \mathrm{g}$ dry lung and that of the right upper and middle lobes was $3.47 \pm 0.09 \mathrm{~g} \mathrm{H}_{2} \mathrm{O} / \mathrm{g}$ dry lung respectively indicating that no fluid had gone to these lobes.

The regional blood content data, plotted in Figure 8, show no significant effect of ventilation and no gravity-dependent gradients.

\section{Light microscopy and grading}

The results of the grading of the interstitial edema are in Figures 9 and 10 . There was more interstitial edema in the left lower lobes in the group ventilated for $60 \mathrm{~min}$ 
compared with the group ventilated for $1 \mathrm{~min}$ when all regions were combined $(P=0.54)$ (Fig. 10). There was no significant oifference in interstitial edema in the right lower lobes between ventilation groups nor between right and left lower lobes. The grading of alveolar edema (Figure 11) showed no significant difference between right and left lower lobes and no gravity-dependent gradient. The large standard errors suggest a heterogeneous distribution of the alveolar edema. When we examined the lungs for atelectasis using the criteria of Zidulka et al (44), we found none.

\section{DISCUSSION}

The principal findings in this study were: 1) the lobes ventilated for 30 and $60 \mathrm{~min}$ had a lower CT density than the unventilated lobes; 2) ventilation had no effect on extravascular lung water nor on regional blood content; 3) gravity-dependent gradients in CT density and extravascular lung water were unaffected by ventilation whereas some reduction in gradients of extravascular water occurred in left lower lobes ventilated for 30 and $60 \mathrm{~min}$; 4) by light microscopy, there was more edema in the interstitium at $60 \mathrm{~min}$ than at $1 \mathrm{~min}$ on the ventilated side only.

We designed our model to study the effects of ventilation on the distribution and clearance of alveolar edema. The 5\% albumin in $6 \%$ dextran-75 that we instilled into the lower lobes had an usmolarity of $302 \mathrm{mOsm} / \mathrm{kg} \mathrm{H}_{2} \mathrm{O}$ and a protein concentration similar to that of serum, as in the studies of Matthay et al $(13,15)$ who instilled $2-3 \mathrm{ml} / \mathrm{kg}$ body weight autologous serum into the lower lobes of sheep. Schultz et al (45) and Berthiaume et al (17) used radiolabeled serum albumin in their instillates to study the clearance of alveolar edem. 
Conhaim et al (46) filled degassed canine lobes with dye-labeled iso-osmotic 5\% albumin solution to study alveolar epithelium permeability. Other methods of inducing edema, in lungs with an intact alveolocapillary barrier, include 1) instillation of crystalloids as in the studies of Matthay et al (13), Gee and Williams (47), and Conhaim et al (48); 2) elevation of Ppaw by intravenous infusion of saline or by inflation of a left atrial balloon, as in the studies of Wickerts et al (33), Pare et al (29) Hedlund et al (35), and Mason et al (49).

In our experiments, we instilled fluid selectively into the lower lobes, and no significant fluid entered the upper and middle lobes since their $\mathrm{Qwl} / \mathrm{dQ}$ l values were normal. Only the left lung was ventilated, and any respiratory movement was prevented by paralyzing the animal, enabling us to compare ventilated and unventilated lungs in the same arimal. We do not believe any significant ventilation of the right lung oscurred since there were no fluctuations in its airway pressure. Our study differs significantly from others in the literature: indeed Matthay et al $(13,15,25)$ compared the clearance of alveolar edema in ventilation with spontaneously breathing sheep, whereas Malo et al (30) and Pare et al (29) studied the effect not only of ventilation, but of PEEP, on the distribution of alveolar versus interstitial edema. The rationale behind the use of CT scanning was to make it clinically relevant by determining overall changes in lung density with ventilation, and to relate the alterations in lung density to changes in lung water and blood content.

Our physiological data showed that compared with pre-instillation, there was significant hypoxia, hypercapnia and acidosis in the 30 and 60 min ventilation groups. This is attributed to the fact that the alveolar edema interfered with gas exchange in both lower lobes, and that only one lung was ventilated, so that the entire gas exchange had taken place 
in the left upper and middle lobes. We found that both Ppa and PVR increased, but only in $60 \mathrm{~min}$ group, due primarily to hypoxic vasoconstriction; other possibilities such as direct compression of vessels either by interstitial or alveolar edema are unlikely (39).

Our data showed a significant fall in CT density of left lower lobes for the 30 and 60 min ventilation groups compared with the unventilated right lower lobes, in the mid-ventral and dorsal regions. There were, however, no differences in the $\mathrm{Qwl} / \mathrm{dQI}$, blood content or amount of atelectasis between the two lungs, so that the differences in density were attributed to the increased aeration of the ventilated lungs. The data are consistent with those of Hedlund et al (50) who found that lung inflation reduced CT density. Our data also indicate that there was no significant clearance of edema fluid from the lungs as a result of ventilation, as shown by the fact the $Q w 1 / d Q 1$ values were unchanged with ventilation (Figs. 6,7).

CT density can be increased due to atelectasis, to intravascular blood content or to edema fluid and is reduced with increased aeration. Gattinoni et al $(37,38)$ showed that in the adult respiratory distress syndrome, 'he increased CT density in the dependent regions, was due largely to compression atelectasis produced by the edema and increased blood volume, and could be prevented by the application of PEEP. In our study, we found using the criteria of Zidulka et al (44), no areas of complete atelectasis even in the right lung. This does not, however, rule out that some diminution in alveolar size might have occurred due to the alveolar edema. Indeed, Malo et al (30) found that the mean linear intercept of flooded alveoli was reduced to about $50 \%$ of that of unflooded alveoli. There were also no differences in Qwl/dQI nor in regional blood content to account for the reduced CT density. 
Therefore, we conclude that the latter is due to the increased aeration produced by ventilation.

This conclusion is also supported by the results of the measurements of lower lobar volumes: after 1 and $30 \mathrm{~min}$ ventilation, we found that the ratio of right/left lower lobes volume was reduced, albeit not attaining statistical significance, to $47 / 53$, compared with the normal of 49/51 (51). By $60 \mathrm{~min}$, however, this ratio was $43 / 57 \mathrm{a}^{\prime}$ ! was indeed statistically significant $(P<0.05)$, consistent with the increased aeration of the left lower lobe increasing its volume.

Although ventilation in the present study increased the aeration of the left lower lobes, it did not promote significant clearance of edema from them since Qwl/dQl values were not altered even after $60 \mathrm{~min}$.

The original aspect of our study is that we compared ventilation with no ventilation, rather than with spontaneous breathing or with the addition of PEEP, and that we used CT scanning to assess changes in lung density. Our literature review revealed that the only other study comparing ventilated with unventilated lungs was by Matthay et al (52) in abstract form, in which they found in both, liquid and protein were cleared at the same rate. Nonetheless, our data are consistent with studies in the literature on the role of ventilation on both aspects of edema clearance, ie. clearance of liquid and solutes from alveoli, and clearance out of the lung as a whole. For example, Matthay et al $(13,15)$ in sheep and Berthiaume et al (31) in dogs found that the clearance of liquid and proteins out of the alveoli and the lung was the same whether the animals were ventilated or spontaneously breathing. 
They concluded that ventilation does not play a role in alveolar liquid clearance which relies largely on active sodium transport, a view supported also by other studies $(2,14-16,27)$.

There is a consensus that mechanical ventilation with PEEP is beneficial in treating the hypoxemia and hypercarbia in clinical and experimental pulmonary edema $(32,53,54)$. The effect of PEEP on the clearance of lung water, however, is controversial. Indeed, in normal canine lungs, Frostell et al (55) found that $\mathrm{Qwl} / \mathrm{dQl}$ was increased by ventilation with PEEP compared with ventilation with zero end expiratory pressure (ZEEP). Demling et al (56) found that Qwl/dQ1 was higher in lobes with venous congestion ventilated with 10 $\mathrm{cmH}_{2} \mathrm{O}$ PEEP compared with $\mathrm{O} \mathrm{cmH}_{2} \mathrm{O}$. Other studies support the notion that PEEP increases Qw1/dQ1 or reduces its clearance in edematous lungs compared with ZEEP $(32,57)$. Bredenberg et al (58) and Hopewell and Murray (59) reported that PEEP had no measurable effect on lung water compared with no PEEP.

There are several potential explanations for the fact that PEEP may not favor edema clearance. First, as proposed by several authors $(55-57,60)$, the elevated lung volumes increase fluid filtration by reducing hydrostatic pressure in the extra-alveolar perimicrovascular interstitial space; second, PEEP, through recruitment of previously atelectatic alveoli, increases the surface area available for transudation of fluid; third, it obstructs pulmonary lymph flow (60), and fourth, although ventilation with PEEP redistributes alveolar edema to the interstitial space, prolonged ventilation or weaning patients from PEEP, could allow the fluid to seep back into the alveoli (57).

The results of these studies conflict in part with those obtained by Pare et al (29) and Malo et al (30) who found in histological studies that ventilation with PEEP enhanced the 
movement of fluid from the alveoli to the interstitium. Therefore, it is plausible, although alveolar edema clearance is largely due to an active ion transport, that ventilation also plays a role. Indeed, our results for histological grading (Fig. 10) show an almost significant $(P=$ 0.054) increase in interstitial edema in lungs ventilated $60 \mathrm{~min}$ compared with $1 \mathrm{~min}$, suggesting a trend for the increased redistribution of fluid from the alveoli to the interstitium with ventilation. These data, taken together with the results of Qwl/dQI measurements (Fig.7) suggest that by $60 \mathrm{~min}$, a small amount of edema moves from the alveoli into the interstitium with ventilation, but that there is no significant clearance of edema from the lung as a whole. The small magnitude of this shift in our experiments was likely due to the fact that the alveolocapillary barrier was intact and that the relatively high protein concentration and osmolarity of the alveolar instillate may hinder movement into the interstitium. In addition, there may not have been enough time for clearance from the alveoli, consistent with the data of Matthay et al (13), who showed that in anesthetized, ventilated sheep, the half time for clearance of crystalloid solutions was $3 \mathrm{~h}$ and of serum instillate was $6 \mathrm{~h}$. The clearance of crystalloids can be increased in dogs and sheep by B-adrenergic agents $(61,62)$, reduced by $50 \%$ with amiloride (25) and prevented by ouabain (14). In contrast, the clearance rate of ${ }^{125} \mathrm{I}$-albumin from the air spaces in anesthetized and unanesthetized dogs and sheep is much slower, averaging $1-1.6 \%$ per hour. Mechanisms that have been proposed for the transalveolar clearance of proteins are transcytosis $(17,18)$, diffusion and muco-ciliary clearance (25). It appears that most of the proteins are cleared by transcytosis across the alveolar epithelium as intact molecules $(15,17,18)$. Macrophages seem to play a role after 48 $h$ by removing from the air space the precipitated proteins that form hyaline membranes 
whereas muco-cilliary clearance into the proximal airways seems to be of minimal importance $(17,25)$.

Our contention that ventilation may play a role in moving fluid out the alveoli is also consistent with the studies by Matthay et al $(2,25)$ who reported that amiloride inhibited only $50 \%$ and $75 \%$ of basal liquid clearance in sheep and in rabbits respectively, leaving a remaining fraction of clearance dependent on a hydrostatic pressure gradient generated by ventilation.

Our data indicated that ventilation also did not measurably affect overall regional blood content. These findings are consistent with those of Frostell et al (60) who showed that in normal dogs, PEEP reduced centrai blood volume by $15 \%$, whereas ventilation with ZEEP had no effect.

In summary, the lower CT density of the left lower lobes ventilated for 30 and $60 \mathrm{~min}$ is due to increased aeration, not to difference in regional Qwl/Qdl, blood content or atelectasis.

Pulmonary edema and CT density are generally believed to be distributed along gravity-dependent gradients (34-36). In our study, we found that there were gravitydependent gradients of CT density and that they were unaffected by ventilation. Hedlund et al (50) in supine baboons, and Rosenblum et al (63) and Morooka et al (64) in humans, reported the presence of ventro-dorsal density gradients by CT of about 200,112 and 46 CTQ, respretively, but they did not determine if they were due to edema, blood or atelectasis. We found gravity-dependent gradients in $\mathrm{Qwl} / \mathrm{dQl}$ in the group ventilated for 1 min, but that they were not significant in the left lower lobes ventilated for 30 and 60 . 
There were no gravity-dependent gradients in blood content. These data are consistent with those of Tsang et al (65) and Schober et al (66) who showed that in hydrostatic pulmonary edema, there $v$ as no gravity-dependent gradient in $\mathrm{Qwl} / \mathrm{dQl}$, contrary to the pulmonary blood flow and volume that were distributed along gravity-dependent gradients. These findings therefore suggest that ventilation may reduce the gravity-dependent edema gradients by redistributing it somewhat from dependent to upper regions. The effect, however, is small.

In conclusion, our study showed that ventilation applied in artificially induced pulmonary edema: 1) increases aeration, thereby decreasing lung CT density; 2) shows a trend to redistribute fluid from alveoli to interstitium; 3) does not influence lung Qwl/dQI clearance.

From a clinical viewpoint, therefore, ventilation acts by increasing aeration of the alveoli, and although it does not appear to clear fluid out of the lungs overall, the fact it redistributes it to the interstitium may also contribute to improving gas exchange. 


\section{REFERENCES}

1. Renkin EM. Some consequences of capillary permeability to macromolecules. Starling's hypothesis reconsidered. Am J Physiol 1986;250:H706-H710.

2. Matthay MA. Resolution of pulmonary edema. New insights. West J Med $1991 ; 154: 315-321$.

3. Vreim CE, Snashall PD, Staub NC. Protein composition of lung fluids in anesthetized dogs with acute cardingenic edema. Am J Physiol 1976;231:1466-1469.

4. Andreadis N, Petty TL. Adult respiratory distress syndrome: problems and progress. Am Rev Resp Dis 1985;132:1344-1346.

5. Demling RH. Current concepts on the adult respiratory distress syndrome. Circulatory Shock 1990;30:297-309.

6. Crandall ED. Recent developments in pulmonary edema. Ann Int Med 1983;99:808822.

7. Lewis JF, Jobe AH. Surfactant and the adult respiratory distress syndrome. Am Rev Respir Dis 1993;147:218-233.

8. Vreim CE, Staub NC. Protein composition of the lung fluids in acute alloxan edema in dogs. Am J Physiol 1976; 230:376-379.

9. Bone RC, Balk R, Slotman G, Maunder R, Silverman H, Hyers TM, Kerstein MD. Adult respiratory distress syndrome. Chest 1992;101:320-326.

10. Fedullo AJ, Swinburne AJ, Wahl GW, Bixby K. Acute cardiogenic pulmonary edema treated with mechanical ventilation. Chest 1991;99:1220-1226. 
11. Pietra GG. New insights into mechanisms of pulmonary edema. J Clin Invest $1984 ; 51: 489-494$.

12. Egan EA. Effect of lung inflation on alveolar permeability to solutes. Ciba Symp 1976;38:101-114.

13. Matthay MA, Landolt CC, Staub NC. Differential liquid and protein clearance from the alveoli of anesthetized sheep. J Appl Physiol 1982;53:96-104.

14. Staub NC. Alveolar flooding and clearance. Am Rev Resp Dis 1983;127:S44-S51.

15. Matthay MA, Berthiaume Y, Staub NC. Long-term clearance of liquid and protein from the lungs of unanesthetized sheep. J Appl Physiol 1985;59:928-934.

16. O'Brodovich. Epithelial ion transport in the fetal and perinatal lung. Am J Physiol 1991;261:C555-C564.

17. Berthiaume Y, Albertine HK, Grady M, Fick G, Matthay MA. Protein clearance from the air spaces and lungs of unanesthetized sheep over $144 \mathrm{~h}$. J Appl Physiol 1989;67:1887-1897.

18. Staub NC. New concepts about the pathophysiology of pulmonary edema. J Thorac Imag 1988;3:8-14.90.

19. Taylor AE. The lymphatic edema safety factor. The role of edema dependent lymphatic factors (EDLF). Lymphology 1990; 23:111-123.

20. Mackarsie RC, Christensen J, Lewis FR. The role of pulmonary lymphatics in the clearance of hydrostatic pulmonary edema. J Surg Res 1987;43:495-504. 
21. Bland RD, Hansen TN, Haberkern CM, Bressack TA, Hayinski J, Raj JU, Goldberg RB. Lung fluid balance in lambs before and after birth. J Appl Physiol 1982;53:9921004.

22. Pearse DB, Wagner EM, Sylvester JT. Edema clearance in isolated sheep lungs. J Appl Physiol 1993;74:126-132.

23. Jayr C, Matthay MA. Alveolar and lung liquid clearance in the absence of pulmonary blood flow in sheep. J Appl Physiol 1991;71:1679-1687.

24. Broaddus VC, Wiener-Kronish JP, Staub NC. Clearance of lung edema into the pleural space of volume-loaded anesthetized sheep. J Appl Physiol 1990;68:26232630.

25. Matthay MA. Resolution of pulmonary edema. Mechanism of liquid, protein, and cellular clearance from the lung. Clin Chest Med 1985;6:521-545.

26. Ali J. The adult respiratory distress syndrome in surgical patients. Ann Roy Coll Phys Surg Can 1987;20:341-345.

27. Matthay MA, Wiener-Kronish JP. Intact epithelial barrier function is critical for the resolution of alveolar edema in humans. Am Rev Respir Dis 1990;142:1250-1257.

28. Bersten AD, Holt AW, Vedig AE, Skowronski GA, Baggoley CJ. Treatment of severe cardiogenic pulmonary edena with continuous positive airway pressure delivered by face mask. N Engl J Med 1991;325:1825-1830.

29. Pare PD, Warriner B, Baile EM, Hogg JC. Redistribution of pulmonary edema extravascular water with positive end-expiratory pressure in canine pulmonary edema. Am Rev Resp Dis 1983; 127:590-593. 
30. Malo J, Ali J, Wood LDH. How does positive end-expiratory pressure reduce intrapulmonary shunt in canine pulmonary edema? J Appl Physiol 1984;57:10021010.

31. Berthiaume Y, Broaddus VC, Gropper MA, Tanita T, Matthay MA. Alveolar liquid and protein clearance from normal dog lungs. J Appl Physiol 1988;65:585-593.

32. Blomqvist H, Wickerts CJ, Berg B, Frostell C, Jolin A, Hedenstierna G. Does PEEP facilitate the resolution of extra-vascular lung water after experimental hydrostatic pulmonary eden:z? Eur Respir J 1991;4:1053-1059.

33. Wickerts CJ, Blomqvist H, Berg B, Rosblad PG, Hedenbstiema G. Furosemide, when used in combination with positive end-expiratory pressure, facilitates the resorption of extravascular lung water in experimental hydrostatic pulmonary edema. Acta Anesthesiol Scand 1991;35:776-783.

34. Stark P, Jasmine J. CT of pulmonary edema. J Thorac Imag 1989;29:245-255.

35. Hedlund LW, Vock P, Effmarn EL, Lischko MM, Putman CE. Hydrostatic pulmonary edema. An analysis of lung density changes by computed tomography. Invest Radiol 1984;19:254-262.

36. Hedlung LW, Vock P, Effmann EL. Evaluating lung density by computed tomography. Resp Med 1983;5:76-88

37. Gattinoni L, D'Andrea L, Pelosi P. Regional effects and mechanism of positive endexpiratory pressure in early adult respiratory distress syndrom. JAMA 1993;269:21222127. 
38. Gattinoni L, Pelosi P, Vitale G, Pesenti A, D'Andrea L, Mascheroni D. Body position changes redistribute lung computed tomographic density in patiens with acute respiratory failure. Anesthesiology 1991;74:15-23.

39. Michel RP, Zocchi L, Rossi A, Cardinal GA, Ploy-Song-Sang Y, Poulsen RS, MilicEmili J, Staub NC. Does interstitial lung edema compress airways and arteries? A morphometric study. J Appl Physiol 1987;62:108-115.

40. Michel RP, Smith TT, Poulsen RS. Distribution of fluid in bronchovascular bundles with permeability lung edema induced by $\alpha$-naphthylthiourea in dogs. Lab Invest $1984 ; 51: 97-103$.

41. Michel RP, Cruz-Orive LM. Application of the Cavalieri principle and vertical sections method to lung: estimation of volume and pleural surface area. J Microsc $1988 ; 150: 117-136$.

42. Michel RP, Laforte M, Hogg JC. Physiology and morphology of pulmonary microvascular injury with shock and reinfusion. J Appl Physiol 1981;50:1227-1235.

43. Vassilyadi $\mathbf{M}$, Michel RP. Pattern of fluid accumulation in $\mathbf{N O}_{2}$-induced pulmonary edema in dogs. A morphometric study. Am J Pathol 1988; 130:10-21.

44. Zidulka A, Chrome JF, Wight DW, Bumett S, Bonnier L, Fraser R. Clapping or percussion causes atelectasis in dogs and influences gas exchange. J Appl Physiol 1989;66:2833-2838.

45. Schultz AL, Grismer JT, Grande F. Absorption of radioactive albumin from the lungs of normal dogs. J Lab Clin Med 1963;61:494-500. 
46. Conhaim RL. Growth rate of perivascular cuffs in liouid-inflated dog lung lobes. J Appl Physiol 1986;61:647-653.

47. Gee MH, Williams Do. Effect of lung inflation on perivascular cuff fluid volume in isolated dog lung lobes. Microvasc Res 1979;17:192-201.

48. Conhaim RL, Gropper MA, Staub NC. Effect of lung inflation on alveolar-airway barrier protein permeability in dog lung. J Appl Physiol 1983; 55:1249-1256.

49. Mason GR, Effros RM, Uszler JM, Mena I. Small solute clearance from the lungs of patients with cardiogenic and noncardiogenic pulmonary edema. Chest 1985;88:327334.

50. Hedlund LW, Vock P, Effmann EL. Computed tomography of the lung. Densitometric studies. Radiol Clin North Am 1983;21:775-788.

51. Rahn H, Ross BB. Bronchial tree casts, lobe weights and anatomical dead space measurements in the dog's lung. J Appl Physiol 1957;10:154-157.

52. Matthay MA, Osorio O, Jayr C. Ventilation is not necessary for normal clearance of excess liquid and protein from the air spaces and interstitium of the sheep lung (Abstr). Clin Res 1990;38:159A.

53. Murray JF, Matthay MA, Luce JM, Flick MR. An expanded definition of the adult respiratory distress syndrome. Am Rev Respir Dis 1988;138:720-723.

54. Rose DM, Downs JB, Heenan TJ. Temporal responses of functional residual capacity and oxygen tension to changes in positive end-expiratory pressure. Crit Care Med $1981 ; 9: 79-82$. 
55. Frostell C, Blomqvist CJ, Hedenstierna G. Lung fluid balance evaluated by the rate of change of extravascular lung water content. Acta Anesthesiol Scand 1990;34:362-369.

56. Demling RH, Staub NC, Edmunds HL. Effect of end-expiratory airway pressure on accumulation of extravascular lung water. J Appl Physiol 1975;38:907-912.

57. Skaburskis $M$, Michel RP, Gatensby A, Zidulka A. Effect of negative-pressure ventilation on lung water in permeability pulmonary edema. J Appl Physiol 1989;66:2223-2230.

58. Bredenberg CE, Kazui T, Webb WR. Experimental pulmonary edema: The effect of positive end-expiratory pressure on lung water. Ann Thorac Surg 1978;26:62-67.

59. Hopewell PC, Murray JF. Effect of continuous positive-pressure ventilation in experimental pulmonary edema. J Appl Physiol 1976;40:568-574.

60. Frostell C, Blomqvist $\mathrm{H}$, Wickerts CJ. Effects of PEEP on extravascular lung water and central blood volume in the dog. Acta Anesthesiol Scand 1987;31:711-716.

61. Crandall ED, Heming TA, Palombo RL, Goodmasn BE. Effects of terbutaline on sodium transport in isolated perfused rat lung. J Appl Physiol 1986;60:289-294.

62. Berthiaume Y, Staub NC, Matthay MA. Beta-adrenergic agonists increase lung liquid clearance in anesthetized sheep. J Clin Invest 1987;79:335-343.

63. Rosenblum LJ, Mauceri RA, Wellenstein DE, Thomas FD, Bassano DA, Raasch BN, Chamberlain CC, Heitzman ER. Density patterns in the normal lung as determined by computed tomography. Radiology 1980;137:409-416. 
64. Morooka N, Watanabe S, Masuda Y, Inagaki Y. Estimation of pulmoih:ry water distribution and pulmonary congestion by computed tomography. Jpn Heart J 1982; 23:697-709.

65. Tsang JY, Baile EM, Hogg JC. Relationship between regional pulmonary edema and blood flow. J Appl Physiol 1986;60:449-457.

66. Schober OH, Meyer GJ, Bossaller C, Creutzig N, Lichtlen PR, Hundeshagen H. Quantitative determination of regional extravascular lung water and regional blood volume in congestive heart failure. Eur J Nucl Med 1985;10:17-24. 
Table 1. Hemodynamic and arterial blood gas results

\begin{tabular}{|c|c|c|c|c|c|}
\hline & \multirow{2}{*}{$\frac{1 \min \text { VENT }}{\text { PRE ED }}$} & \multicolumn{2}{|c|}{$30 \mathrm{~min} V E N T$} & \multicolumn{2}{|c|}{$60 \min$ VENT } \\
\hline & & PRE ED & POST ED & PRE ED & POST ED \\
\hline Psys (mmHg) & $137 \pm 8$ & $144 \pm 10$ & $155 \pm 11$ & $139 \pm 9$ & $140 \pm 8$ \\
\hline $\mathrm{Ppa}(\mathrm{mmHg})$ & $12.2 \pm 1$ & $14 \pm 0.9$ & $18.3 \pm 1$ & $16 \pm 1$ & $19.6 \pm 1^{*}$ \\
\hline Ppaw (mmHg) & $4.0 \pm 0.4$ & $6.5 \pm 0.9$ & $9 \pm 1.8$ & $6.3 \pm 1.0$ & $9.1 \pm 1.4^{*}$ \\
\hline$\dot{\mathrm{Q}}_{\mathrm{T}}(\mathrm{l} / \mathrm{min})$ & $2.3 \pm 0.3$ & $2.5 \pm 0.5$ & $2.6 \pm 0.4$ & $3.7 \pm 0.7$ & $2.2 \pm 0.3$ \\
\hline PVR(mmHg.min. $\left.1^{-1}\right)$ & $3.9 \pm 0.9$ & $3.2 \pm 0.4$ & $3.9 \pm 0.6$ & $3.4 \pm 0.9$ & $5.1 \pm 1^{*}$ \\
\hline $\mathrm{PO}_{2}(\mathrm{mmHg})$ & $78 \pm 5$ & $94 \pm 4$ & $41 \pm 3^{*}$ & $93 \pm 5$ & $46 \pm 2^{*}$ \\
\hline $\mathrm{PCO}_{2}(\mathrm{mmHg})$ & $41 \pm 3$ & $28 \pm 3$ & $43 \pm 2^{*}$ & $34 \pm 3$ & $47 \pm 2^{*}$ \\
\hline pH & $7.35 \pm 0.05$ & $7.42 \pm 0.04$ & $7.25 \pm$ & $7.40 \pm 0.03$ & $7.22 \pm$ \\
\hline
\end{tabular}

Values are mean $\pm \mathrm{SE} ;{ }^{*} \mathrm{P}<0.05$ vs pre-edema

Psys, systemic arterial pressure; Ppa, pulmonary arterial pressure; Ppaw, pulmonary

arterial wedge pressure; $\dot{\mathbf{Q}}_{\mathrm{T}}$, cardiac output; PVR, pulmonary vascular resistance;

pre ed, pre-edema; post ed, post-edema; vent, ventilation 


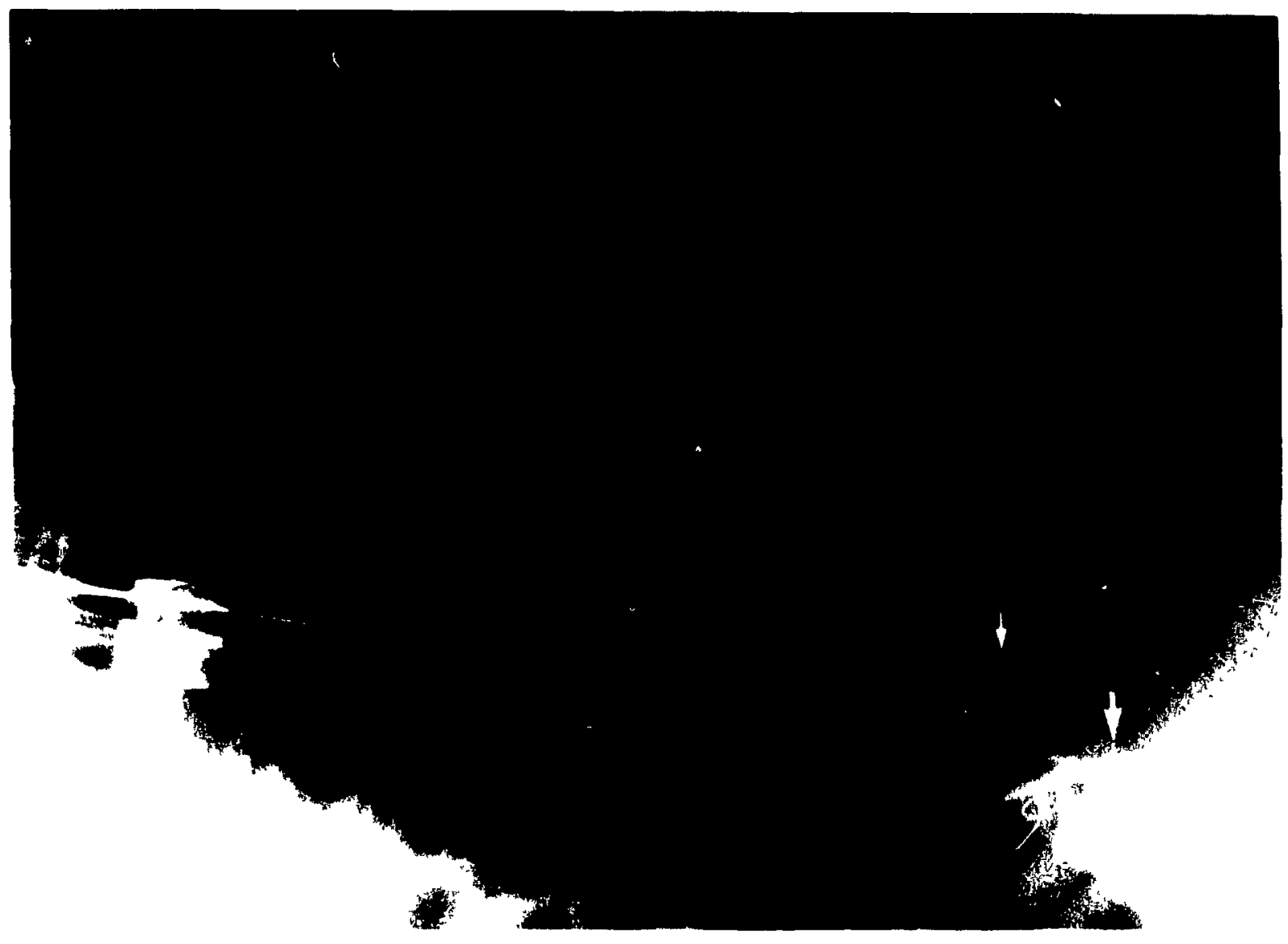

Fiqure 1. Lateral X-ray of the thorax of one dog in the supine position showing the Swan-Ganz catheters introduced through the divided tracheal tube. The tips of the Swan-Ganz catheters (arrows) are placed at the same level in the most dependent position of the left and right lower lobes. The third Swan-Ganz catheter seen was introduced for the hemodynamic measurements. The vertebral column is inferior, the diaphragm on the right and the sternum superior in this figure. 


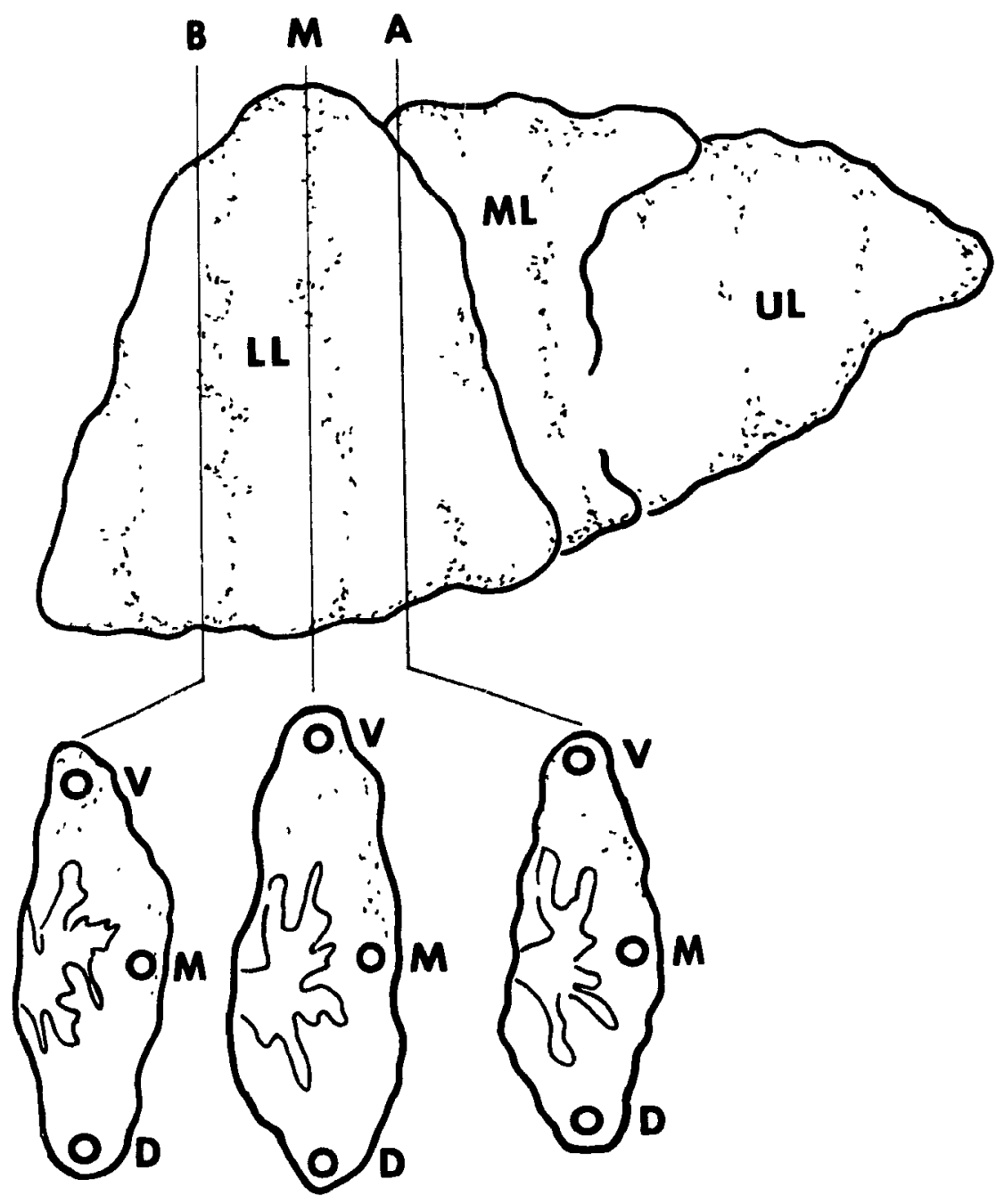

Figure 2. Diagram of a lateral view of the left lung of a dog in supine position: $A, M$ and $B$ are the respective apical, middle and basal levels of the $5 \mathrm{~mm}$ transverse CT scan sections of the lower lobes. On each section, the positions of the ROI's are represented: $\mathbf{V}=$ ventral, $\mathbf{M}=$ mid-ventral and $\mathrm{D}=$ dorsal. $\mathrm{UL}$ $=$ upper lobe, $\mathrm{ML}=$ middle lobe and $\mathrm{LL}=$ lower lobe. 


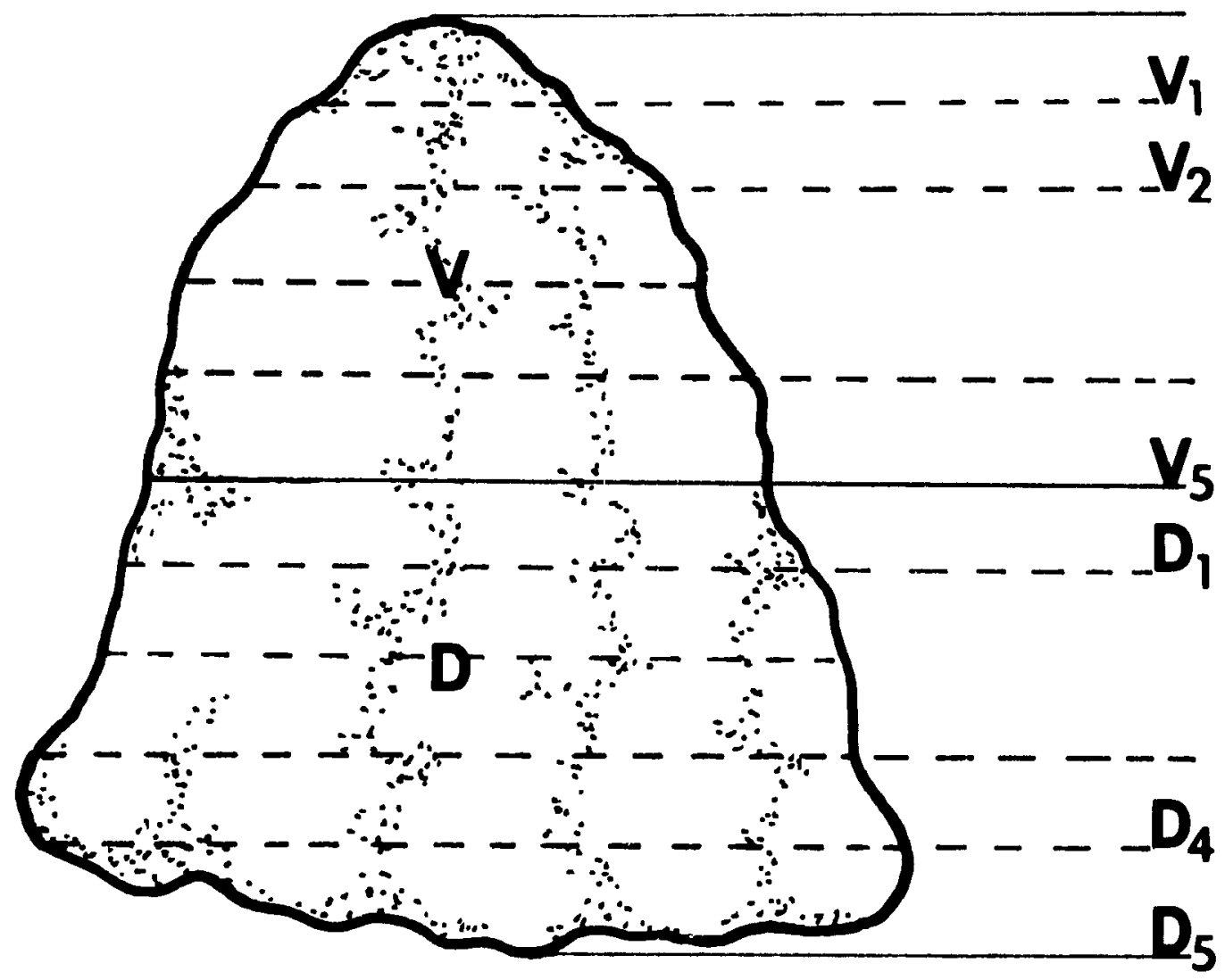

Figure 3. Diagram of the left lower lobe (lateral view) showing sites of sampling for histology and extravascular lung water measurements. V and D are the ventral and dorsal halves, respectively. $V_{1}$ and $V_{2}$ were sampled for the ventral region, $V_{5}$ and $D_{1}$ for the mid-ventral, and $D_{4}$ and $D_{5}$ for the dorsal region of each lower lobe, corresponding to the CT regions. 

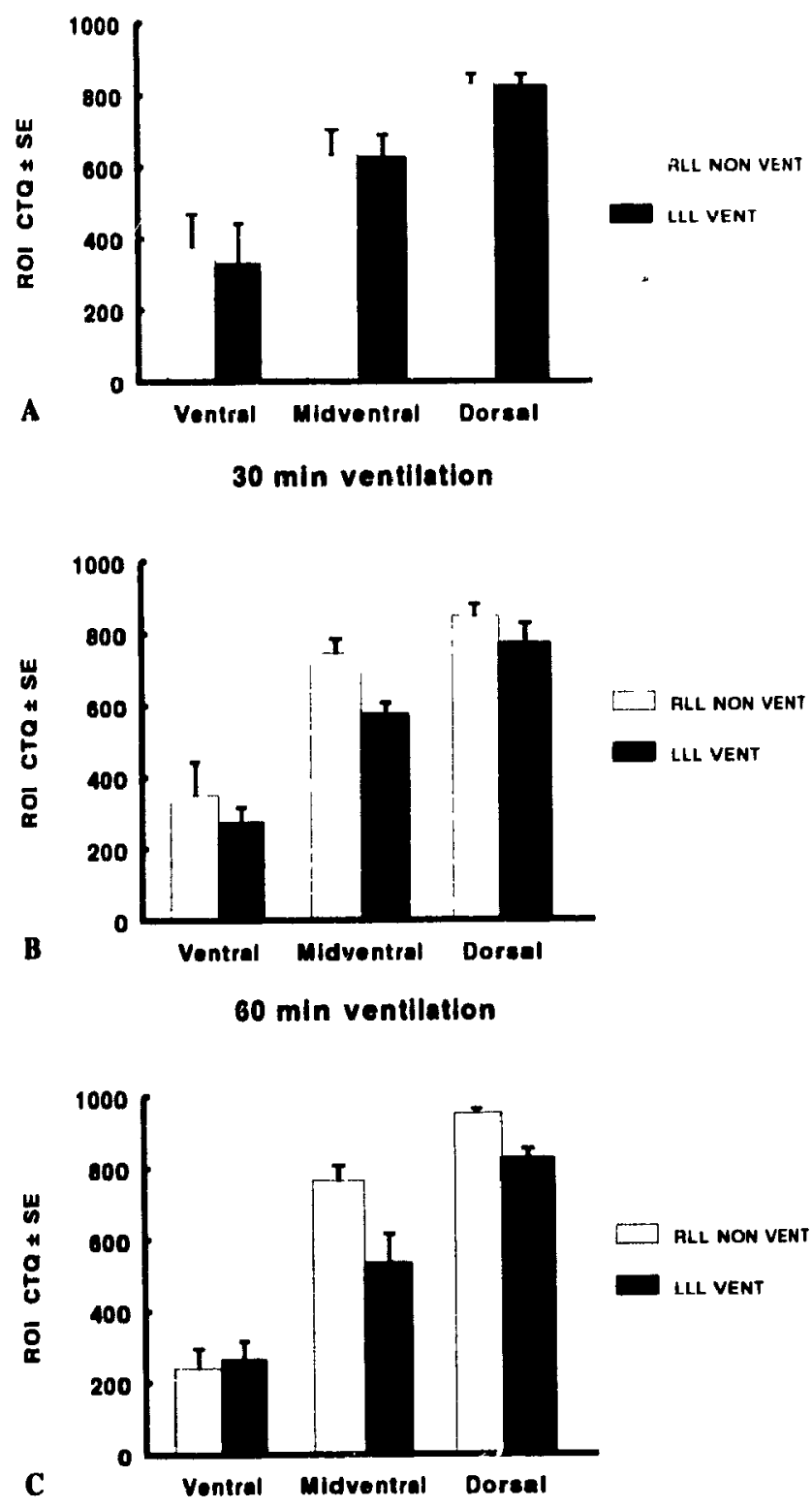

Disure 4. ROI CTQ values for the different gravity-dependent regions of the right and left lower lobes at $1 \mathrm{~min}(\mathrm{~A}), 30 \mathrm{~min}(\mathrm{~B})$ and $60 \mathrm{~min}(\mathrm{C})$ ventilation. There were significant gravity-dependent gradients in CTQ values from ventral to dorsal regions for all three groups $(P<0.05)$. For the 30 and $60 \mathrm{~min}$ ventilation groups, the CTQ values for the left mid-ventral and dorsal regions were significantly lower $(P<0.05)$ than on the right. 


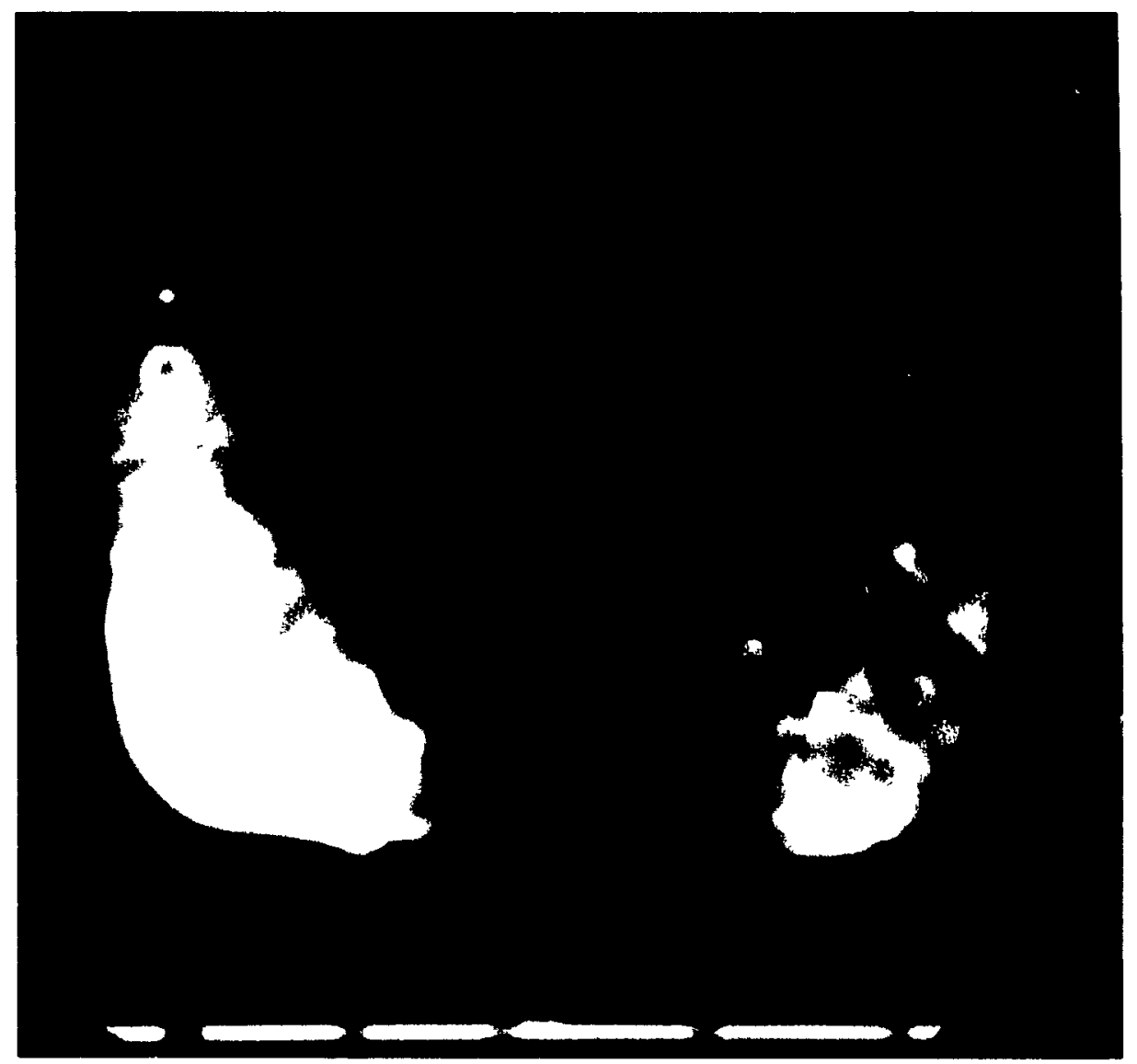

Figure 5. Representative $5 \mathrm{~mm}$ transverse CT scan taken at the basal level of a right and a left (L) lower lobe from a $60 \mathrm{~min}$ ventilation experiment. Note the reduced density of the dependent regions in the left lobe compared with the right. 

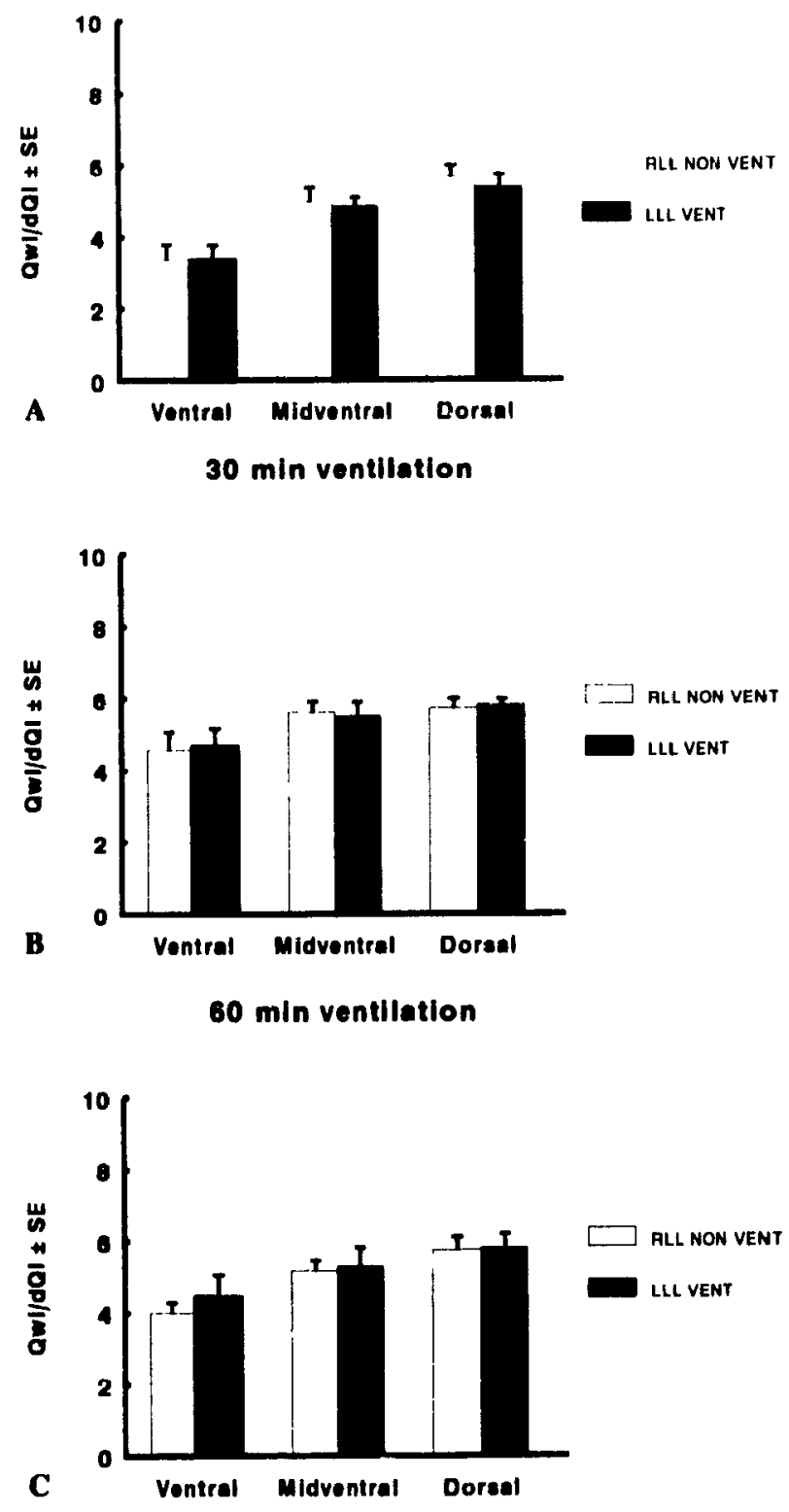

Diqure 6. Extravascular lung water (Qwl/dQl) measurements by region in the right and left lower lobes at $1 \mathrm{~min}(\mathrm{~A}), 30 \mathrm{~min}(\mathrm{~B})$, and $60 \mathrm{~min}(\mathrm{C})$ ventilation. There was a significant gravity-dependent gradient in left lower lobes ventilated for 1 min that was absent after ventilation for 30 and $60 \mathrm{~min}$. 


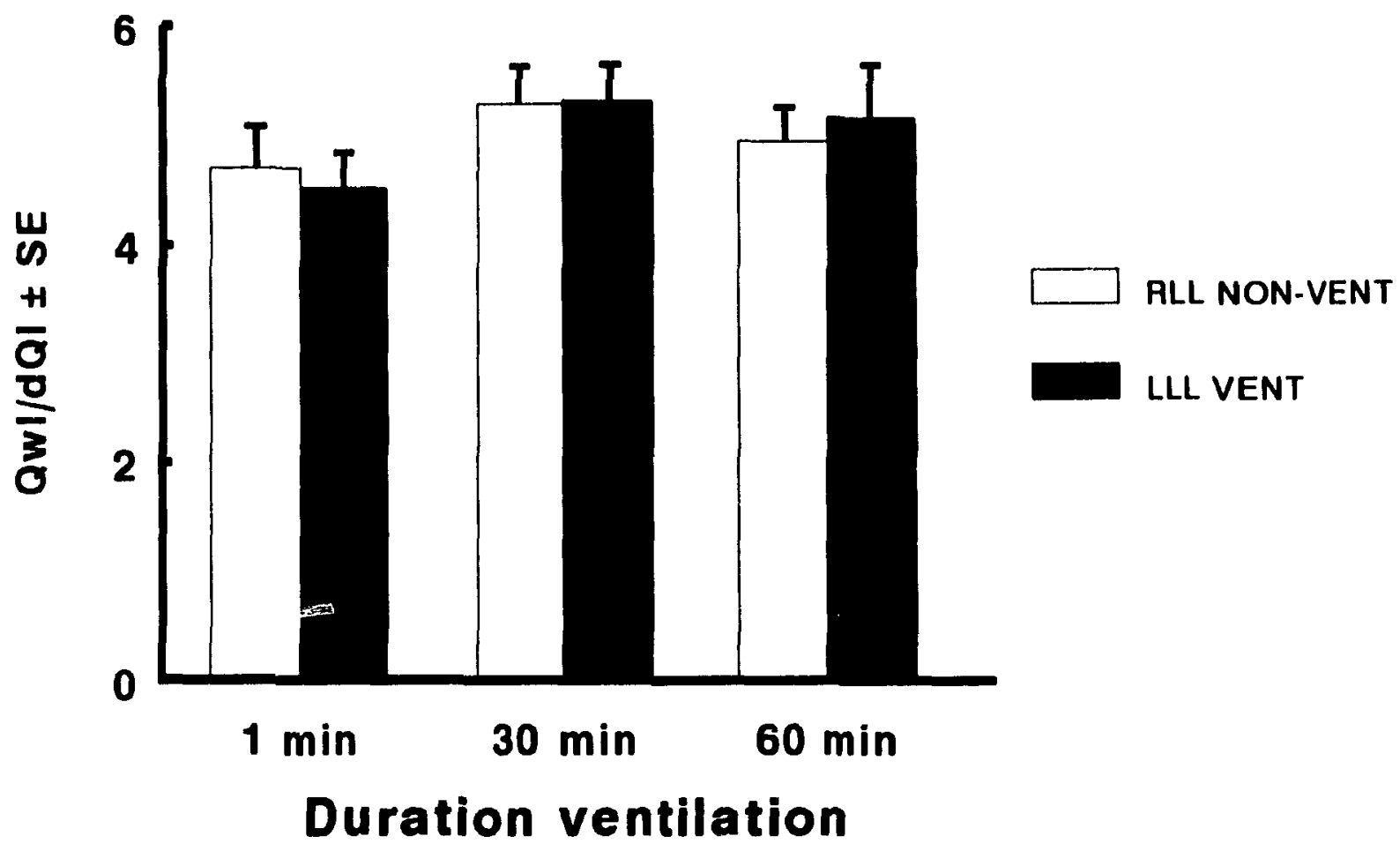

Fiqure 7. Qwl/dQI measurements expressed as means of all regions, from right and left lower lobes. No significant differences were observed. 


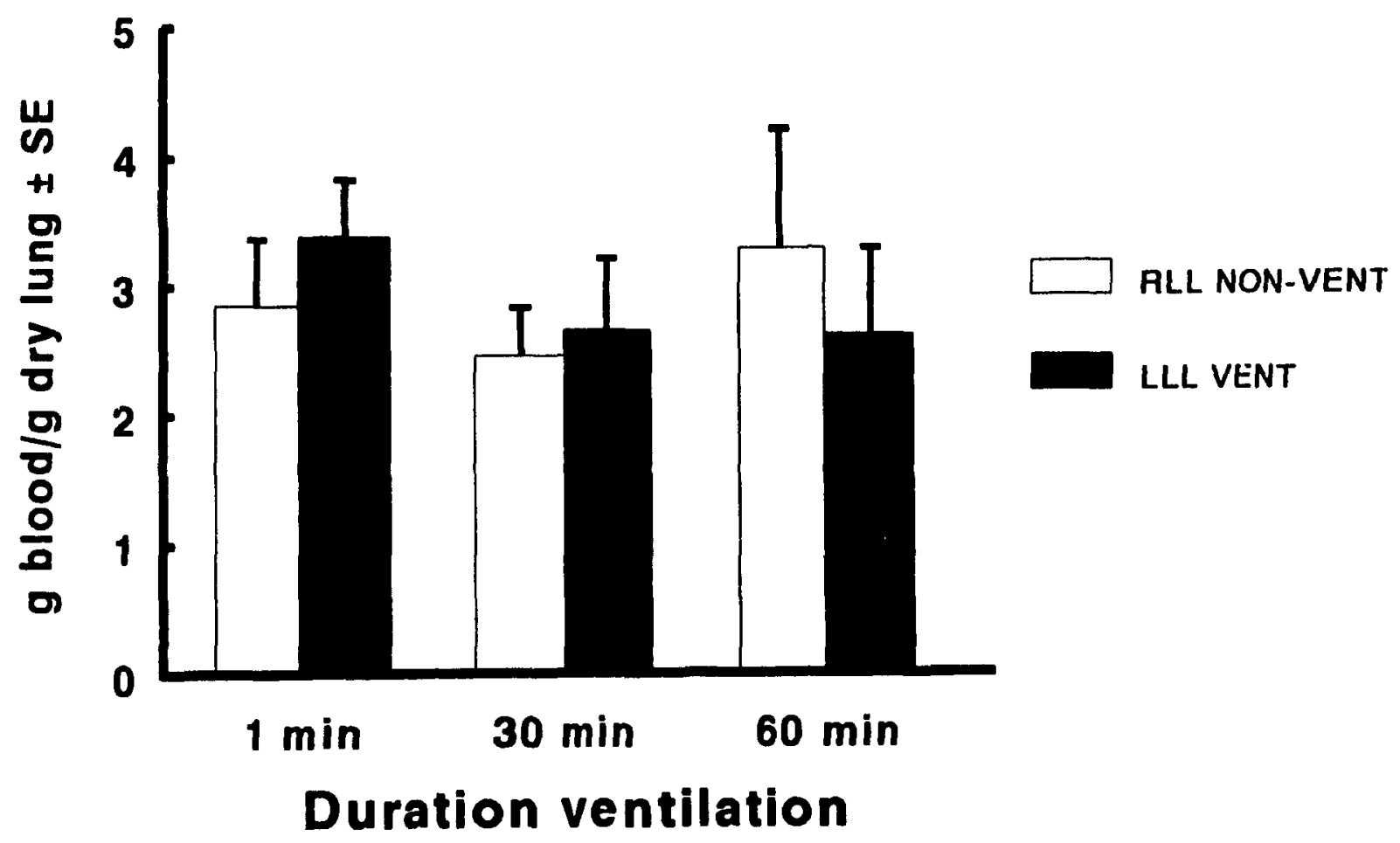

Eleure 8. Blood content in $\mathrm{g}$ blood/g dry lung expressed as means of all regions for right and left lower lobes. No significant differences were observed. 
1 min ventilation
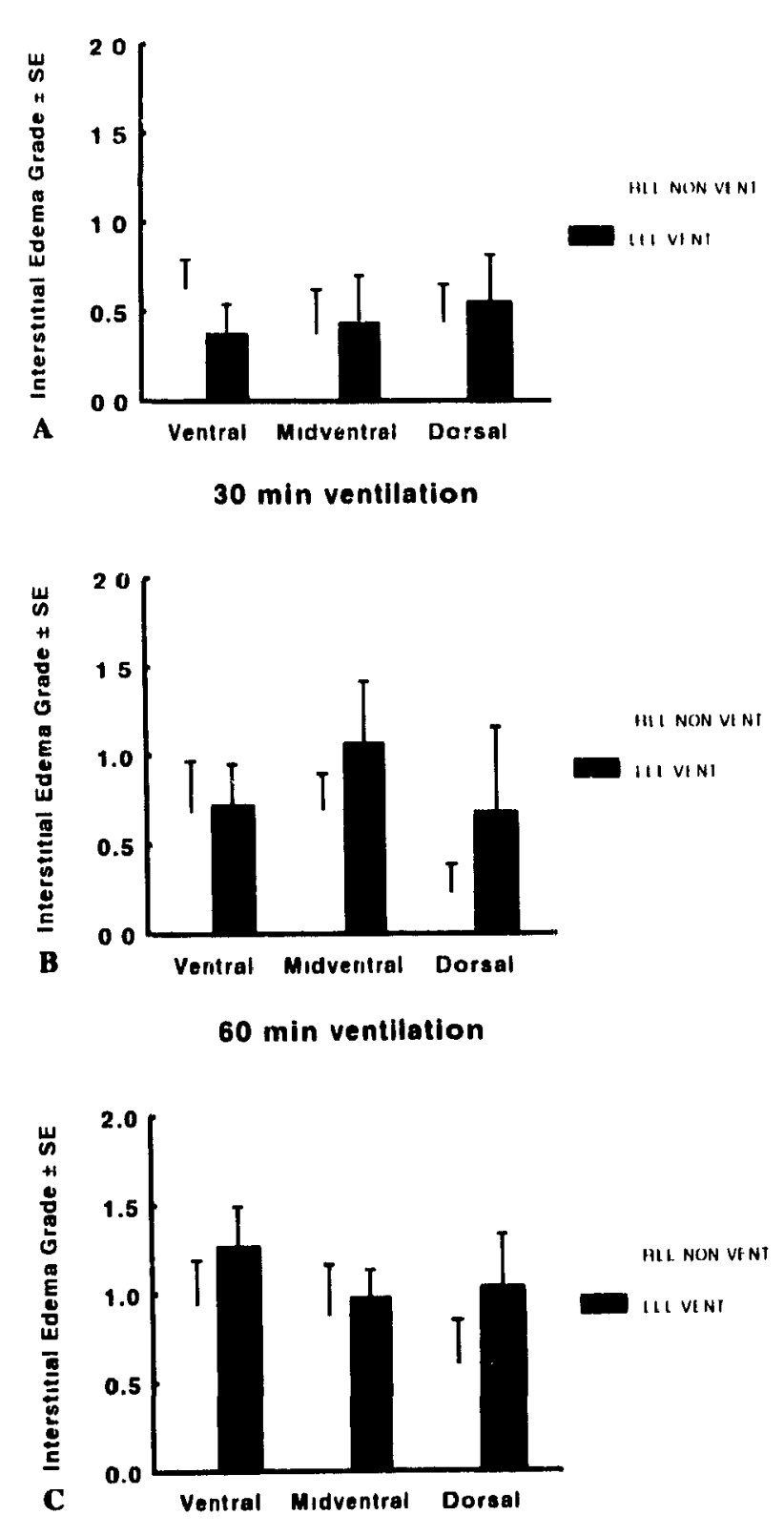

Fiqure 9. Interstitial edema grade of right and left lower lobes by regions for $1 \mathrm{~min}(\mathrm{~A})$, $30 \mathrm{~min}(\mathrm{~B})$ and $60 \mathrm{~min}(\mathrm{C})$ ventilation, determined by light microscopy. No significant differences were observed when individual values were considered. 


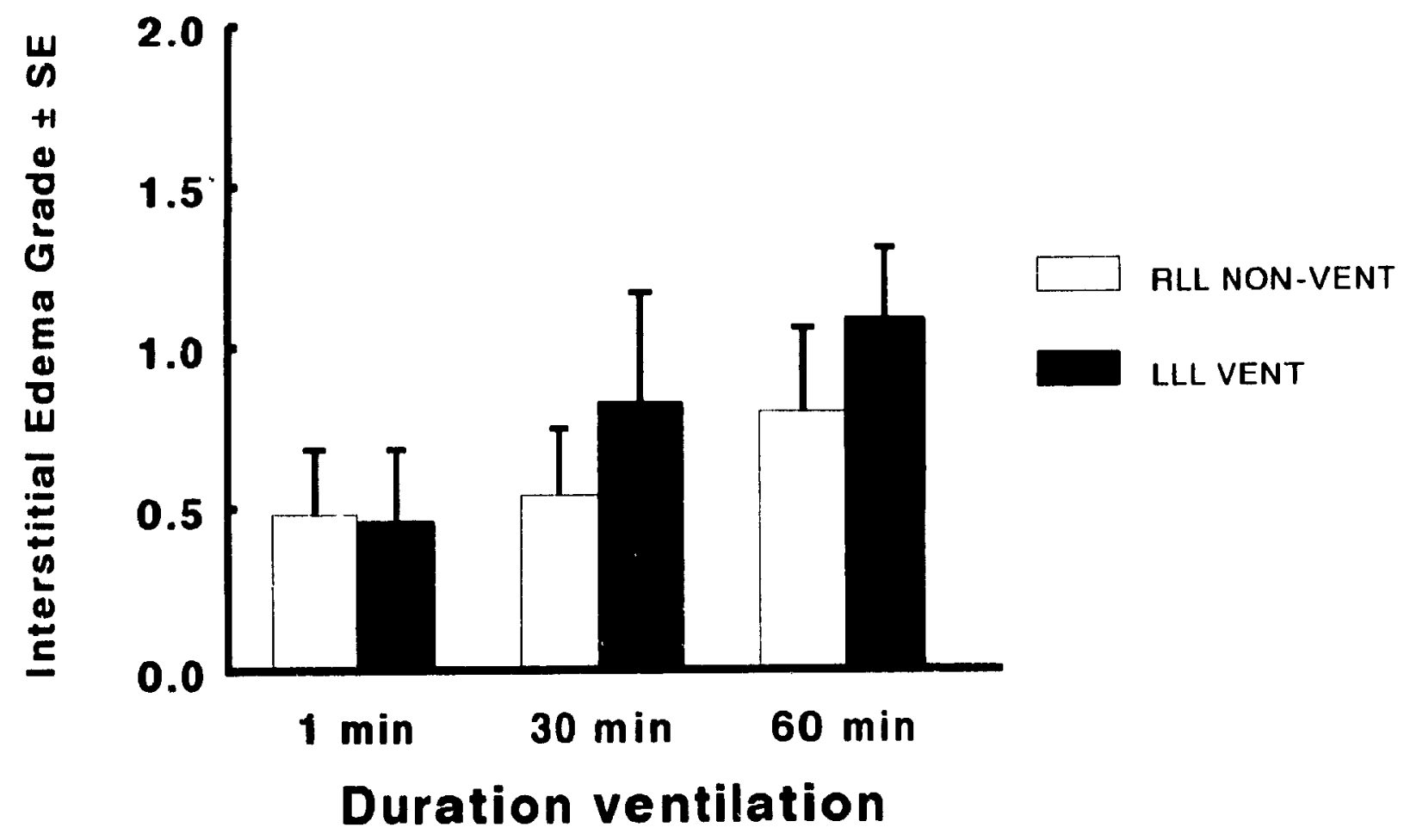

Eigure 10. Interstitial edema grade expressed as mean of all regions of right and left lower lobes. There was a borderline significant $(P=0.054)$ increase in interstitial edema in the left lower lobes in the $60 \mathrm{~min}$ compared with the 1 min ventilation group. 
1 min ventilation
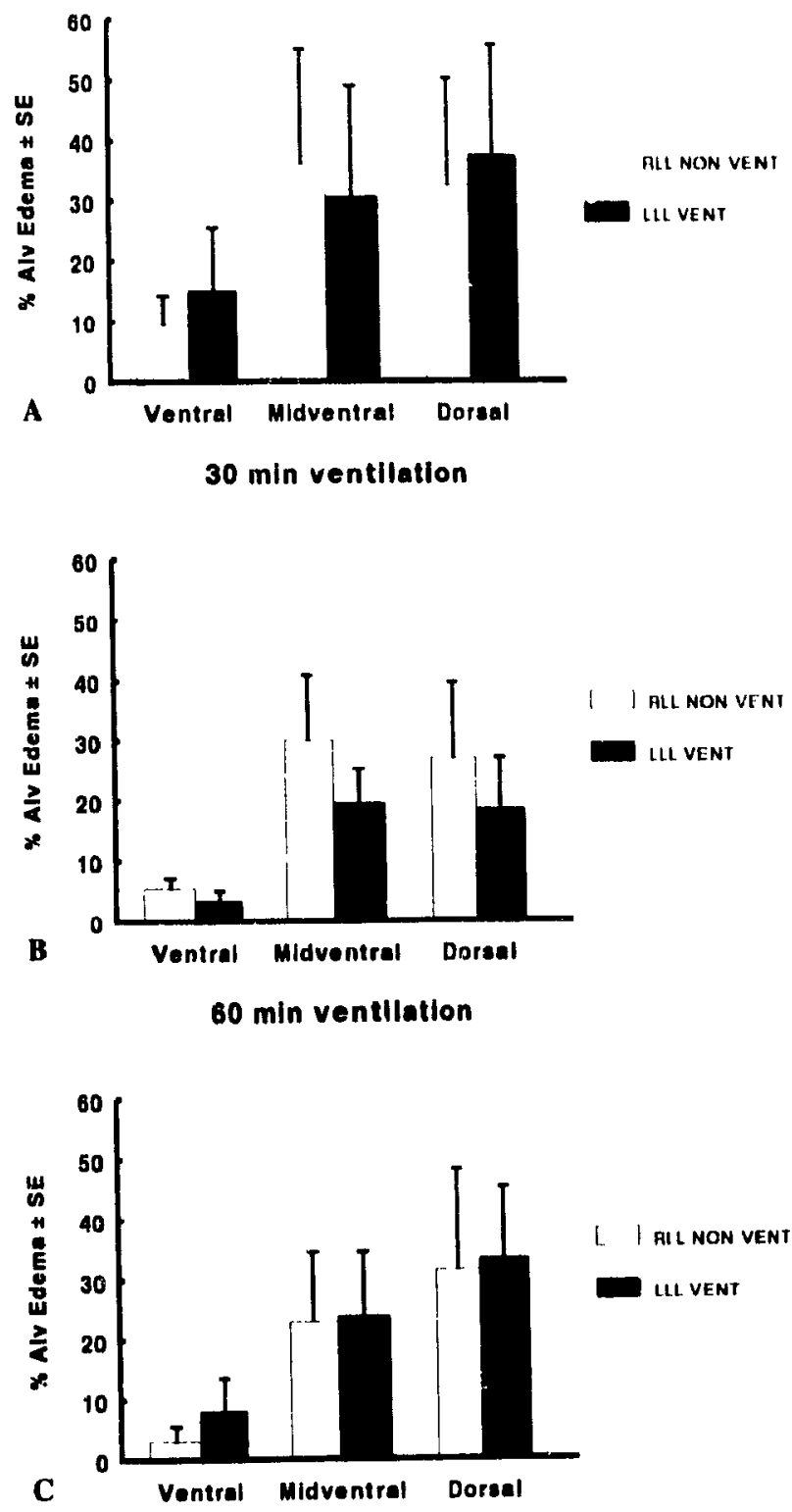

Figure 11. Percent alveolar edema for different regions of the right and left lower lobes at $1 \min (\mathrm{A}), 30 \mathrm{~min}(\mathrm{~B})$ and $60 \mathrm{~min}$ (C) ventilation, determined by light microscopy. Despite apparent differences between the ventral and the other two regions, no statistically significant difference could be demonstrated due to the large standard error. 


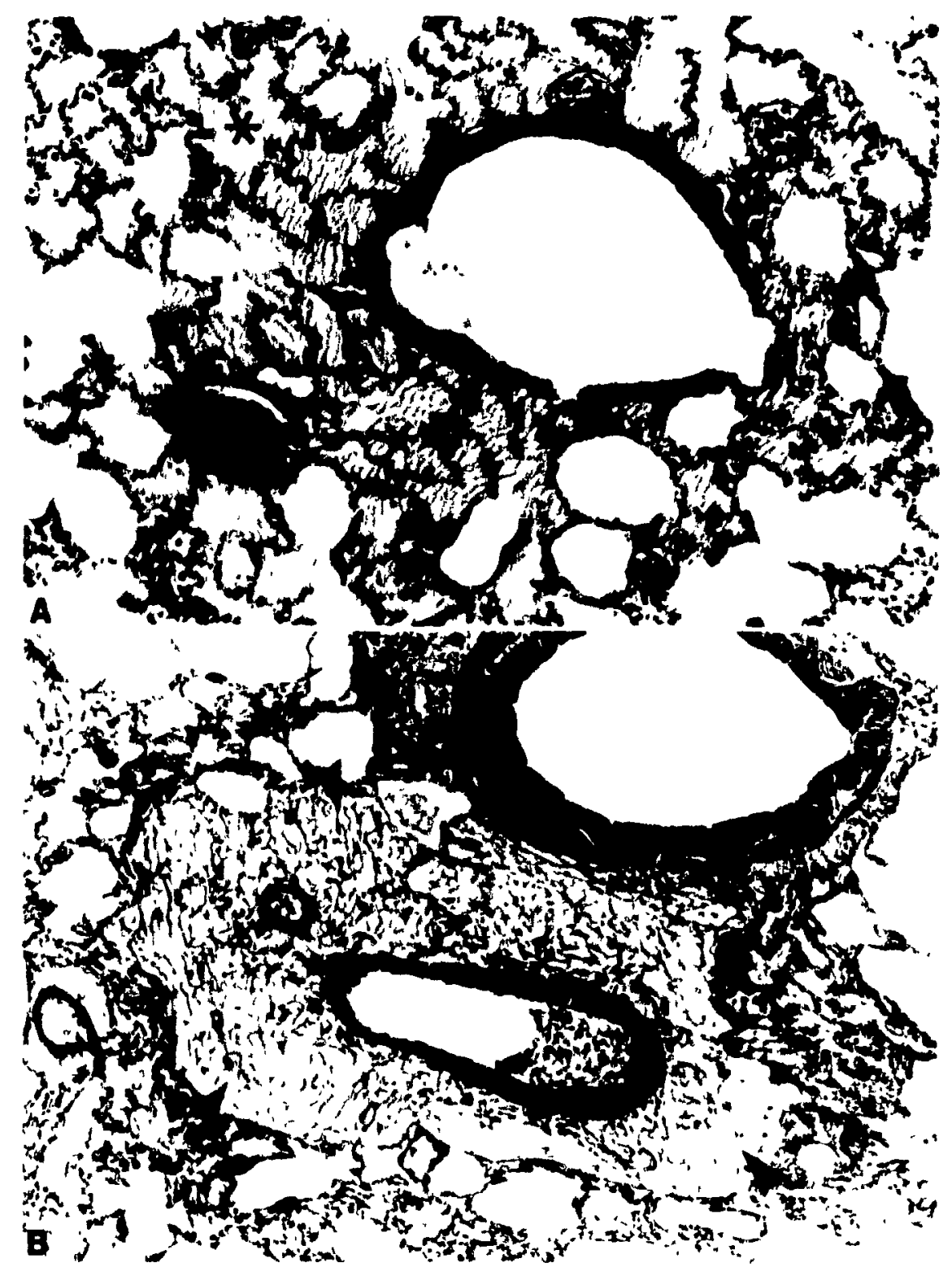

Fiqure 12. Representative light photomicrographs of histological sections of left lower lobes after Carnoy's fixation. A) Bionchovascular bundle from a lobe in the group ventilated for $1 \mathrm{~min}$. Note abundant alveolar edema $\left(^{*}\right)$ and no visible interstitial edema. H \& E X 50. B) Bronchovascular bundle from a lobe in the group ventilated for $60 \mathrm{~min}$. Note the prominent perivascular interstitial edema (arrowhead). H \& E X 50. 
78

CHAPTER 3

CONCLUSIONS 
The objectives of the present study as presented in the Introduction (Chapter 1) were all achieved. Specifically, we used CT scanning to examine the effects of ventilation compared with the absence of ventilation, on the distribution of pulmonary edema in canine lobis; changes in lung density were related to measurements of extravascular lung water and blood content obtained by gravimetry, and to estimates of atelectasis, interstitial and alveolar edema obtained by light microscopic semiquantitative grading.

The important conclusions of the study are reviewed below.

1. Our model enabled us to ventilate only the left lung, leaving the right unventilated. Any significant movement of air in the latter is unlikely since airway pressure did not fluctuate. Essentially all other studies of this problem, apart from one in abstris : form only (see Discussion, Chapter 2), have studied the effects of PEEP, or of ventilation compared with spontaneous breathing.

The instillate used to produce the alveolar edema had a relatively high protein concentration, similar to that of serum. This enabled its visualization with light microscopy. The resultant osmotic pressure produced by the protein probably explains in part the absence of significant clearance of the edema from lungs by $60 \mathrm{~min}$. The edema fluid was selectively instilled into the lower lobes and no significant amounts entered the upper and middle lobes, as supported by the fact their extravascular water contents were normal. 
2. Our physiological measurements after $\mathbf{3 0}$ and $60 \mathrm{~min}$ indicated the presence of hypoxia, hypercapnia and acidosis. This is not surprising since all the gas exchange occurred in the left upper and middle lobes, the left lower lobes being largely filled with edema and the right lung remaining unventilated. The arterial blood gas abnormalities were sufficient to raise Ppa and pulmonary vascular resistance, mainly via hypoxic vasoconstriction.

3. The principal finding by CT scanning was that ventilation for 30 and 60 min resulted in a reduced CT density in the left lower lobes. This reduced CT density can be attributed to a decrease in edema, in blood content, or in atelectasis. Our study was designed to determine the mechanism of the change in CT density and sinre blood content and extravascular lung water did not change, and since we saw no atelectasis in either the right or left lungs, we attributed the decreased density to increased aeration of the left lower lobe compared with the unventilated side. It is noteworthy that, despite the absence of atelectasis in these lobes, as reported by Malo et al (see Discussion, Chapter 2), when there is alveolar edema, alveolar size, as measured by mean linear intercept, is in fact reduced. This suggests that there is partial atelectasis of individual alveoli, not visualized as complete alveolar collapse seen by the usual criteria. What ventilation appears to be doing, therefore, is to reverse this phenomenon, and increase the aeration of the lung. Our results, in this respect, are supported by our finding that the left lower lobar volumes were higher than those on the right side, particularly in the group ventilated for $60 \mathrm{~min}$. 
4. Although ventilation reduced CT density, it had no effect on the Qwl/dQ1 values. This indicates that by $60 \mathrm{~min}$, no significant effect of ventilation on clearance of edema from the lung was found. Although these data are consistent with several others in the literature, this is the first study to examine this problem using CT scanning combined with conventional methods to assess lung water and blood content. The reasons for the lack of significant clearance are elaborated in greater detail in Chapter 2, and revolve around the relatively high protein content of the edema fluid, a short time of ventilation and the fact that the alveolo-capillary barrier was intact. Nevertheless, there was some movement of fluid, over this period, from the alveoli to the interstitium, and this process appeared to be accelerated by ventilation. These results therefore suggest that even when the alveolocapillary barrier is intact, fluid and protein move more rapidly out of the alveoli with ventilation, process which should also contribute to ameliorate gas exchange.

5. Another objective of our study was to examine gravity-dependent gradients of CT density, Qwl/dQl and blood content. In normal lungs, there is a gravity-dependent CT density gradient attributable primarily to increased basal blood flow. In edema, this blood flow and content tend to be redistributed, so that they are evenly distributed from the top to the bottom of the lungs. In our study, this was indeed the case. We did find, however, a gradient in CT density attributed to a gradient of lung water, and that ventilation reduced the latter, it did not alter the gravity-dependent gradient in CT density. This suggests that ventilation primarily increased aeration of the lung but also, by aerating primarily the part of 
the lung with the greater amount of edema, seems to have moved some of the fluid to the less dependent areas. This effect, however, was not very large.

In summary, we can conclude trom the present study that ventilation reduces the CT density of the lung by increasing asation rather than moving fluid out of the lung as a whole. This appears to be the principal mechanism whereby gas exchange is improved. Nonetheless, ventilation also appears to promote the movement of fluid into the interstitium, and this may contribute to some extent to improving gas exchange by reducing the amount of alveolar edema. Data from the literature suggest that PEEP further accelerates this process and also contributes to the aeration of the alveoli by keeping them open throughout the respiratory cycle. The present study, therefore, provides further evidence of the rationale for ventilation of patients in pulmonary edema and provides explanation for alteration in lung density obtained by CT scanning, procedure frequently performed in the assessment of this and other forms of lung disease. 
APPENDIX I

ABBREVIATIONS 


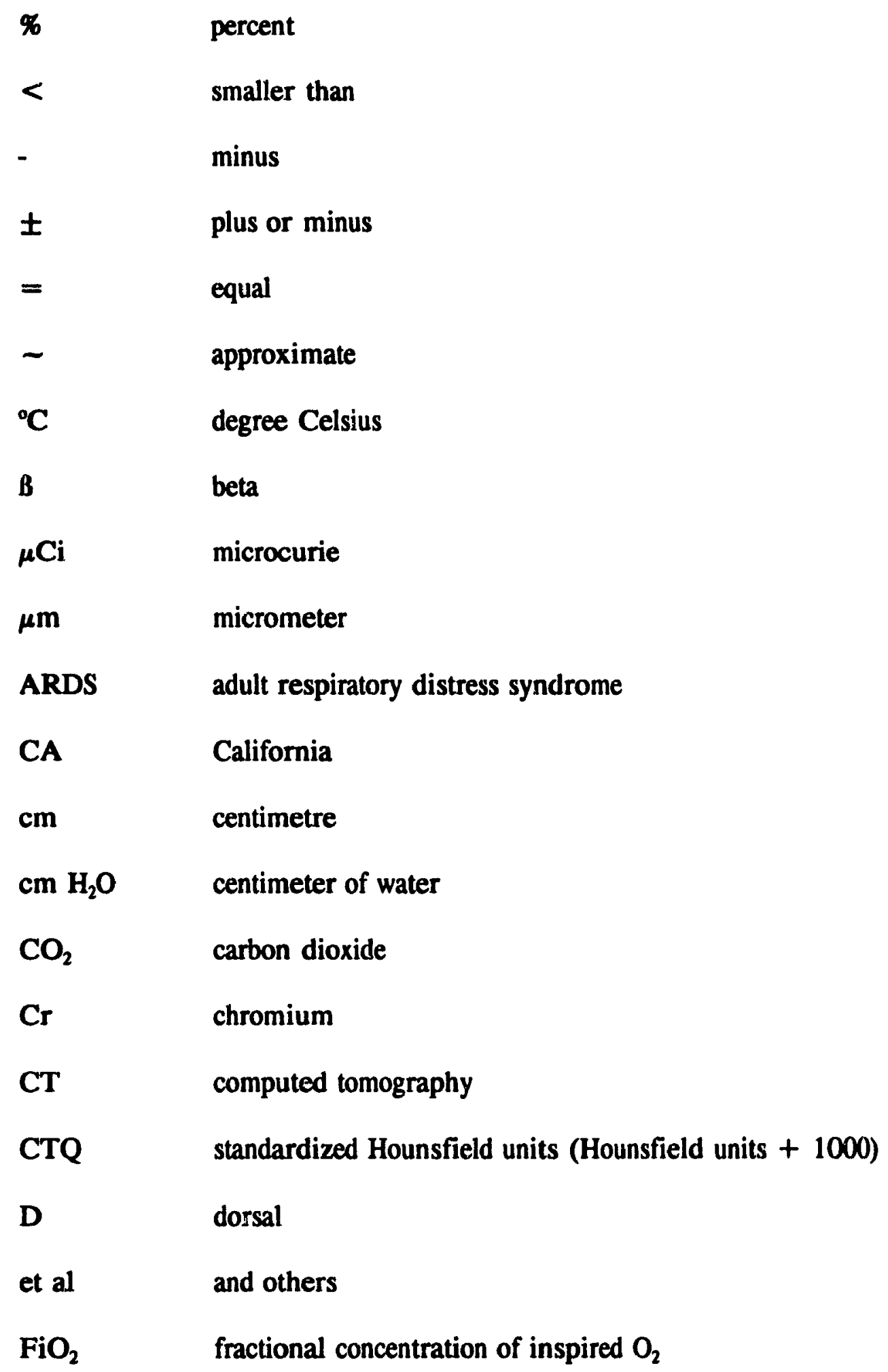




\begin{tabular}{|c|c|}
\hline Fig. & figure \\
\hline 8 & gram \\
\hline $\mathbf{h}$ & hour \\
\hline$\left[\mathbf{H}^{+}\right]$ & concentration of protons \\
\hline HU & Hounsfield units \\
\hline $\mathrm{H}_{2} \mathrm{O}$ & water \\
\hline i.e. & that is to say \\
\hline kg & kilogram \\
\hline $\mathbf{k V}$ & kilovolt \\
\hline $\mathrm{KCl}$ & potassium chloride \\
\hline $\log$ & logarithm \\
\hline LL & lower lobe \\
\hline $\mathbf{m A}$ & milliampere \\
\hline mg & milligrams \\
\hline $\min$ & minute \\
\hline ml & milliliter \\
\hline $\mathbf{m m}$ & millimeter \\
\hline $\mathbf{m m}^{2}$ & squared mm \\
\hline $\mathrm{mOsm} / \mathrm{kg} \mathrm{H} \mathrm{H}_{2} \mathrm{O}$ & milliosmoles per $\mathrm{kg} \mathrm{H}_{2} \mathrm{O}$ \\
\hline $\mathbf{M}$ & mid-ventral \\
\hline MA & Massachussetts \\
\hline ML & middle lobe \\
\hline
\end{tabular}


n

$\mathrm{O}_{2}$

$\mathrm{OsO}_{4}$

P

$\mathrm{pCO}_{2}$

pH

$\mathrm{pO}_{2}$

PEEP

Ppa

Ppaw

Psys

PVR

Qw1/dQ1

$\dot{\mathbf{Q}}_{\mathrm{T}}$

ROI

SE

UL

v

ZEEP

X-ray number

oxygen

osmium tetroxide

probability that the difference is due to chance

partial pressure of $\mathrm{CO}_{2}$ in the arterial blood

$-\log \left[\mathrm{H}^{+}\right]$

partial pressure of $\mathrm{O}_{2}$ in the arterial blood

positive end-expiratory pressure

pulmonary arterial pressure

pulmonary arterial wedge pressure

systemic arterial pressure

pulmonary vascular resistance

extravascular lung water

cardiac output

region of interest

standard error

upper lobe

ventral

zero end-expiratory pressure

roentgenogram 
APPENDIX II

\section{S.I. UNIT EQUIVALENTS}


cm $\mathrm{H}_{2} \mathrm{O}$

$98 \mathrm{~Pa}$

$\mathrm{mmHg}$

$133 \mathrm{~Pa}$ 


\section{APPENDIX III}

\section{ACKNOWLEDGEMENTS}


I want to thank to Dr R.P. Michel for his support and criticism in pursuing this study. The accuracy, relevance and clarity of the material in this study benefited from his diligent supervision.

My distinguished friend and fellow Marvin Zwikler, MSc, helped and encouraged me continuously along this study.

Dr Hu Fu was always very cooperative and helpful in his technical assistance.

I would like to thank the friendly staff at the computing tomography scanning department of the Montreal Neurologic Hospital for CT technical assistance, i.e. Louis Botero, Carollyn Hurst and Garry Clarke.

Laura Fiorita and Stella Totilo were remarkable friends and consultants in secretarial matters.

I wish to thank all my good friends in the department of Pathology for their friendly environment.

Finally, my gratitude for my best friend Corina, who still believes in me and supports me. 